OPEN ACCESS

Edited by:

Toshinari Maeda,

Kyushu Institute of Technology, Japan

Reviewed by:

Dae-Hee Lee,

Korea Research Institute of Bioscience and Biotechnology (KRIBB),

South Korea

Shen-Long Tsai,

National Taiwan University of Science and Technology, Taiwan

*Correspondence:

Nicholas V. Coleman

Nicholas.coleman@sydney.edu.au

Specialty section:

This article was submitted to

Synthetic Biology,

a section of the journal

Frontiers in Bioengineering and

Biotechnology

Received: 29 October 2021

Accepted: 09 December 2021

Published: 10 January 2022

Citation:

Moratti CF, Scott C and Coleman NV (2022) Synthetic Biology Approaches to Hydrocarbon Biosensors: A Review. Front. Bioeng. Biotechnol. 9:804234. doi: 10.3389/fbioe.2021.804234

\section{Synthetic Biology Approaches to Hydrocarbon Biosensors: A Review}

\author{
Claudia F. Moratti ${ }^{1,2}$, Colin Scott ${ }^{2}$ and Nicholas V. Coleman ${ }^{1 *}$ \\ ${ }^{1}$ School of Life and Environmental Science, Faculty of Science, University of Sydney, Sydney, NSW, Australia, ${ }^{2}$ CSIRO Synthetic \\ Biology Future Science Platform, Canberra, ACT, Australia
}

Monooxygenases are a class of enzymes that facilitate the bacterial degradation of alkanes and alkenes. The regulatory components associated with monooxygenases are nature's own hydrocarbon sensors, and once functionally characterised, these components can be used to create rapid, inexpensive and sensitive biosensors for use in applications such as bioremediation and metabolic engineering. Many bacterial monooxygenases have been identified, yet the regulation of only a few of these have been investigated in detail. A wealth of genetic and functional diversity of regulatory enzymes and promoter elements still remains unexplored and unexploited, both in published genome sequences and in yet-tobe-cultured bacteria. In this review we examine in detail the current state of research on monooxygenase gene regulation, and on the development of transcription-factor-based microbial biosensors for detection of alkanes and alkenes. A new framework for the systematic characterisation of the underlying genetic components and for further development of biosensors is presented, and we identify focus areas that should be targeted to enable progression of more biosensor candidates to commercialisation and deployment in industry and in the environment.

Keywords: biosensor, hydrocarbon, alkane, alkene, monooxygenase, transcription factor, regulation, bacteria

\section{INTRODUCTION}

Synthetic biology repurposes the native functions of organisms to engineer creative solutions to problems. The metabolic diversity of bacteria is among their most useful properties for synthetic biology; this feature is the product of millions of years of evolutionary adaptation to diverse niches, nutrients, and stresses. Hydrocarbon-metabolising bacteria are especially interesting for synthetic biology applications, including bioremediation (Das and Chandran, 2011), biocatalysis (Coscolín et al., 2019), and biosensors (Sticher et al., 1997).

Nearly eighty different bacterial genera have been identified as degraders of at least one petrochemical, although only a fraction are genetically or biochemically well-characterised. Monooxygenases are the key enzymes responsible for bacterial degradation of alkanes and alkenes in such bacteria, and the regulatory systems of monooxygenases are therefore of significant interest. There is a need to better characterise these sensing systems to better understand the metabolic diversity of bacteria and to capitalise on these biological switches.

Several eukaryotic species are also capable of hydrocarbon degradation, including many genera of fungi and yeast, and one alga (Prince, 2010). Similarly to bacterial systems, monooxygenases are responsible for the eukaryotic metabolism of aliphatic alkanes. To date only the cytochrome P450 class of monooxygenases have been identified to perform this role (Das and Chandran, 2011; Prenafeta-Boldu et al., 2019) and only under aerobic conditions, unlike in bacteria where hydrocarbon metabolism is facilitated by several classes of monooxygenases and can also occur 


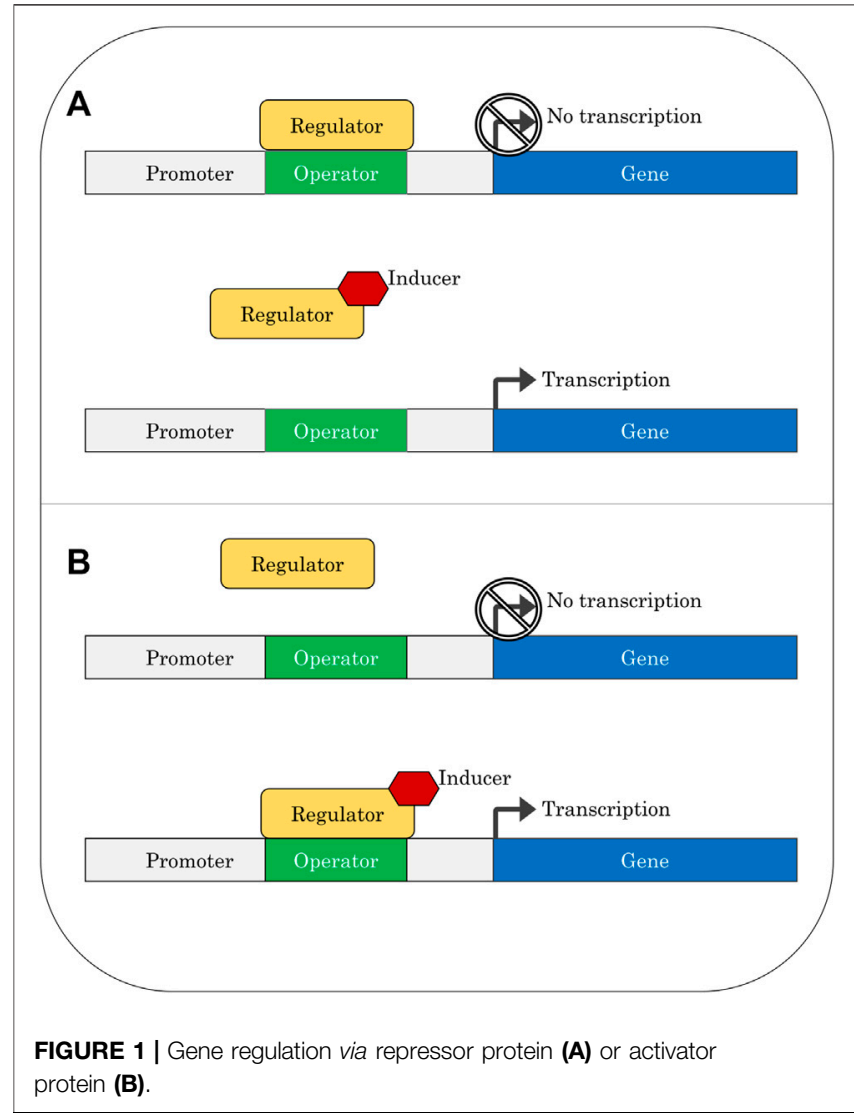

anaerobically. In fungal systems, other types of hydrocarbons including alkenes and polycyclic aromatics are typically only partially degraded and it is rare for hydrocarbons to act as a sole carbon source (Prince, 2010; Prenafeta-Boldu et al., 2019). Eukaryotic hydrocarbon degradation has already been extensively reviewed (Cerniglia and Crow, 1981; Prince, 2010; Das and Chandran, 2011; Beier et al., 2014; Prenafeta-Boldu et al., 2019) and so is not included in the scope of this review. Moreover, the variety of monooxygenases involved in bacterial hydrocarbon degradation is interesting and warrants a narrow focus, especially when considering these systems for biotechnology applications.

Hydrocarbon-sensing systems consist of regulatory proteins (transcription factors) that bind to an inducer and then interact with operator sequences near the promoter of the gene being controlled, resulting in a change in expression levels of that gene (Figure 1). In some cases, the sensing system is divided into two proteins, one which binds the inducer, and another which interacts with the operator; the induction signal in these cases is passed from the first protein to the second. A promoter is a sequence of DNA upstream of a gene that recruits RNA polymerase for transcription (Browning and Busby, 2016). Operators act as binding sites for specific transcription factors and have features including direct or inverted repeats. An inducer is a compound that interacts with the regulatory protein in a way which changes the binding of the protein to the operator.
A regulatory protein is considered a repressor if it binds to the operator in the absence of an inducer, preventing transcription. An inducer will relieve repression by binding to the protein in a way that prevents the protein from remaining bound to the operator. In contrast, activators are regulatory proteins that only bind to the operator once they have complexed with an inducer; in these cases, transcription will be switched on after binding of the activator protein. Transcription-factor-based biosensors can be easily constructed from these regulatory components by replacing the metabolic genes normally controlled by the system with a readily detectable output such as fluorescence. The broad use of bacterial two-component systems in biosensors has been recently reviewed (Lazar and Tabor, 2021).

There has been much research into the bacterial metabolism and detection of aromatic hydrocarbons (Chauhan et al., 2008; Plotnikova et al., 2016; Reineke et al., 2020). Less is known about metabolism and sensing of aliphatic hydrocarbons, in particular the shorter chain gaseous compounds. Development of biosensors for detection of $n$-alkanes and $n$-alkenes has mostly been aimed at monitoring the clean-up of oil spills in seawater (Harayama et al., 2004; Tecon and Van der Meer, 2008; Tecon et al., 2010; Das and Chandran, 2011; Reed et al., 2012; Zhang et al., 2012a; Sevilla et al., 2017; Varjani, 2017), with a consequent focus on biosensor systems detecting octane (Jiang et al., 2020) and bacterial hosts suited to marine environments (Sevilla et al., 2015). The limited scope of research on aliphatic biosensors is unfortunate given their potentially many applications.

Aliphatic hydrocarbon biosensors are potentially useful in the chemical industry for real-time monitoring of reactants or products (Minak-Bernero et al., 2004), in the fresh produce industry for the detection of ethene (Janssen et al., 2014), and in the natural gas industry for both safety and maintenance applications (e.g., leak detection) (Nandimandalam et al., 2018). There has also been interest in the biofuels industry in biosensors for detecting the intracellular concentrations of biosynthesized alkanes ( $\mathrm{Wu}$ et al., 2015). Finally, there are potential medical applications for alkane biosensors in analysis of breath samples for lung cancer diagnosis (Tan et al., 2016).

This review will provide a framework for the development of transcription-factor based biosensors to help guide future development efforts. The framework will then be used to assess the current research landscape in the case of aliphatic hydrocarbons, including review of the bacteria and catabolic enzymes associated with these substrates, the types of regulatory genes involved, and consideration of the limiting factors in the research development pipeline. Methods commonly used to fulfil the requirements of each step of the framework will also be summarised throughout.

\section{A FRAMEWORK FOR BACTERIAL BIOSENSOR DEVELOPMENT}

A framework has been developed here to show the key stages in the development of transcription-factor-based biosensors; this includes clear research goals that must be achieved to progress 
CYP153 monooxygenase p450 from A.borkumensis SK2

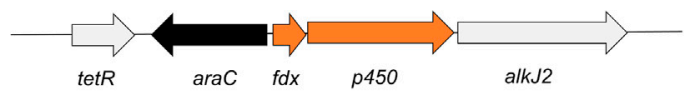

Group 3 SDIMO monooxygenase bmo from T.butanivorans
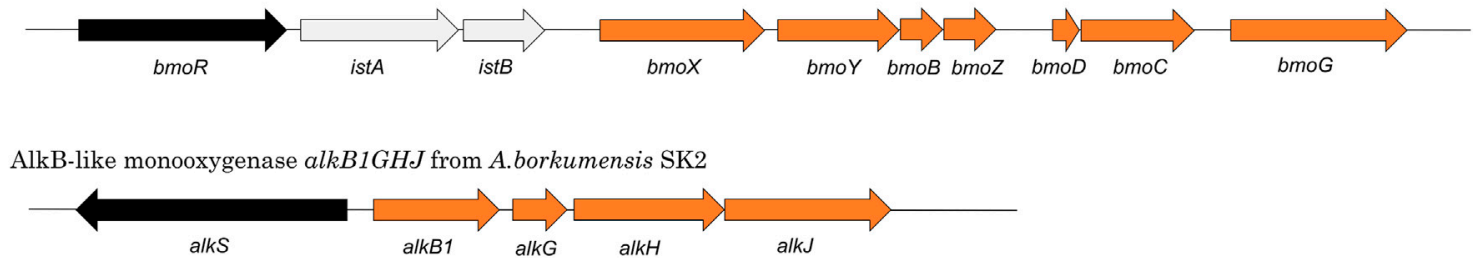

AlkB-like monooxygenase alkB2 from A.borkumensis SK2

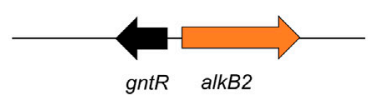

AlkB-like monooxygenase alkBFGHJKL/alkST from P.putida Gpo1

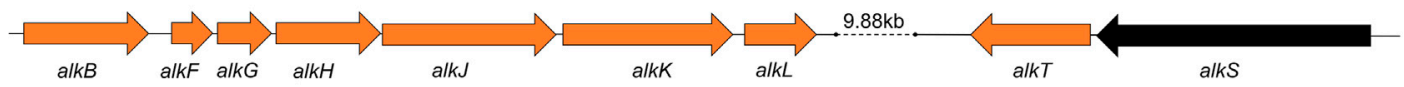

AlkB-like monooxygenase alkM from Acinetobacter sp. ADP1

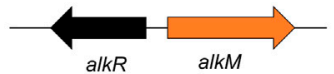

AlkB-like monooxygenase alkB from Dietzia sp. DQ12-45-b1

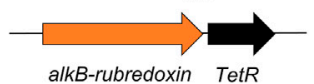

FIGURE 2 | Representative monooxygenase gene clusters showing relative arrangements of metabolic genes (orange) and regulatory genes (black).

from concept to deployment. When applied to the biosensor literature to date, this framework allows identification of the limiting steps, which is important to focus funding and research in the areas which will provide the most reward for effort.

The first step in the development of any biosensor is the identification of a biological part that could be repurposed for a sensing application; this might be an enzyme, antibody or nucleic acid (van der Meer, 2010). Research then progresses to characterisation, where the function of the candidate sensor is confirmed. This is usually done via the deletion and/or complementation of the gene and/or promoter element in the presence of the predicted inducer compound(s). Characterisation may be done in stages depending on how the sensing system was first discovered. For example, if it was found associated with specific catabolic genes, the function of these is often first confirmed before the associated sensing elements are characterised.

The third checkpoint in biosensor development is proof-ofconcept in a controlled laboratory environment. At this stage, various key parameters such as sensitivity, selectivity, shelf life and response time would be determined. Next is the development phase, where the biosensor circuitry and context are adapted with the intention of optimising those key parameters. Finally, the device can proceed to be engineered for market deployment. This stage includes activities such as: seeking regulatory approval, benchmarking analysis, production scale-up, process optimisation, cellular immobilisation, and company formation.

Applying the above framework to the specific case of aliphatic hydrocarbon biosensors typically involves two rounds of identification and characterisation. First, a monooxygenaseencoding gene is identified, and the corresponding enzyme function is characterised. Secondly, the transcription factor responsible for monooxygenase expression is identified and the regulatory mechanism of the system is characterised. There will be a strong focus on the characterisation strategies for these regulatory mechanisms in this review because it is at this stage where greater research efforts are most needed, as will be made apparent.

\section{IDENTIFICATION AND CHARACTERISATION OF MONOOXYGENASES}

Identification of a biological part may be deliberate or coincidental, rigorous or speculative. Bioinformatic detection could be targeted at the transcription factor itself, or at the associated catabolic genes. The identification stage typically 
TABLE 1 | Organisation and properties of bacterial monooxygenases involved in aliphatic hydrocarbon degradation.

\section{Monooxygenase family}

SDIMO: Soluble di- Group

iron

monooxygenases
Group 3, includes
sMMOs: soluble
methane

monooxygenases

\section{Description}

Contains 4 protein subunits $\left(\alpha_{2} \beta_{2} \gamma_{2}\right)-C-F-R, \quad x y l e n e s$, styrene, naphthalene, encoded by 6 genes Small and Ensign (1997), Zhou et al. (1999) indole, $\mathrm{C}_{2}-\mathrm{C}_{6}$ alkenes, $\mathrm{C}_{2}$ chloroalkenes, chloroform isoprene Ensign et al. (1992)

\begin{tabular}{ll} 
& $\begin{array}{l}\text { Group 3, includes } \\
\text { sMmOs: soluble } \\
\text { methane } \\
\text { monooxygenases }\end{array}$ \\
& Group 4 \\
& \\
& Group 5 \\
& \\
\hline CuMmo: Copper & includes pMmOs: \\
monbrane & Particulate methane \\
monooxygenases
\end{tabular}

Contains 4 protein subunits $\left(\alpha_{2} \beta_{2} \gamma_{2}\right)-C-X-R$ encoded by 6 genes Murrell et al. (2000), Banerjee et al. (2019)

Contains 3 protein subunits $(\alpha \beta)-C-R$ Saeki and Furuhashi (1994), Miuran and Dalton. (1995) Contains 3 protein subunits $^{\mathrm{b}}(\alpha \beta)-\mathrm{C}-\mathrm{R}$ encoded by 4 genes Kotani et al. (2003)

\section{Contains 3 protein} subunits ${ }^{\mathrm{b}}(\alpha \beta)-\mathrm{C}-\mathrm{R}$ encoded by 4 genes Kotani et al. (2007)

\section{Contains 3 protein} subunits $\left(\alpha_{3} \beta_{3} \gamma_{3}\right)$ encoded by 3 genes Lieberman and Rosenzweig (2004)
$\mathrm{C}_{1}-\mathrm{C}_{9}$ alkanes and haloalkanes, $\mathrm{C}_{2}-\mathrm{C}_{4}$ alkenes and haloalkenes, $\mathrm{C}_{1}-\mathrm{C}_{2}$ ethers, cyclohexane, benzene, toluene, styrene, pyridine, methanol Dubbels et al. (2007)

$\mathrm{C}_{2}-\mathrm{C}_{10}$ alkenes and haloalkenes, $\mathrm{C}_{5}-\mathrm{C}_{9}$ cycloalkenes Miuran and Dalton (1995), Cheung et al. (2013)

Propane, tetrahydrofuran, dioxane, dioxolane, chloroethylether, methyl tertbutyl ether, $\mathrm{N}$-nitrosodimethylamine Vainberg et al. (2006), Sharp et al. (2007)

\section{Propane, tetrahydrofuran,} dioxane Deng et al. (2018)

Inducer(s)

benzene, toluene, xylenes,

methylphenols,

chlorophenols, $\mathrm{C}_{2}-\mathrm{C}_{4}$ (chloro)alkenes,

epoxyisoprene Ensign.

(1996), Arenghi et al. (1999), Arenghi et al. (2001), Silva-Jiménez et al. (2012), Crombie et al. (2015)

low Cu/biomass ratio

(sMMO only), n-butanol (BMO) Hanson and Hanson (1996), Kurth et al. (2008)

Epoxyalkanes encoded by 4 genes

\section{C2-C6 alkanes,}

tetrahydrofuran, $\beta$ -

hydroxyethoxyacetic acid

Kotani et al. (2006), Sales

et al. (2013)

propane, butane, tetrahydrofuran, dioxane Kotani et al. (2006)

\section{C1-C5 alkanes and} haloalkanes, C2-C4 alkenes and haloalkenes, C2-C4 ethers Stirling et al. (1979), Burrows et al. (1984), Johnson et al. (2004)

Contains 3 protein
subunits $\left(\alpha_{3}\right)$-F-R
encoded by 3 genes
Smits et al. (2002),
Alonso and Roujeinikova
(2012)

$\mathrm{C}_{3}-\mathrm{C}_{13}$ alkanes, $\mathrm{C}_{10}-\mathrm{C}_{20}$ alkanes, propylene, 1-butene van Beilen et al. (1994), Johnson and Hyman (2006)

\author{
Soluble methane \\ monooxygenase \\ MmoXYBZDC.from \\ Methylococcus capsulatus \\ Bath Stainthorpe et al. \\ (1990), Rosenzweig et al. \\ (1993) \\ Ethene monooxygenase \\ EtnABCD from \\ Mycobacterium chubuense \\ NBB4 Coleman et al. (2006), \\ Coleman et al. (2011a)
}

Propane monooxygenase PrmABCD from Gordonia TY-5 Kotani et al. (2003)
High copper/biomass ratio Particulate methane (pMMO only) Hanson and monooxygenase PmoCAB Hanson (1996), propane, from Methylococcus butane, tert-butyl alcohol, capsulatus Bath Stolyar et al. C4-C6 ethers Johnson et al. (2001) (2004)
Alkane hydroxylase AlkBFGHJKL from et al. (2011), dicyclopropylketone Moreno Pseudomonas putida Gpo1 and Rojo. (2019) van Beilen et al. (1994). AlkMa from Acinetobacter sp. M1 Tani et al. (2000), Throne-Holst et al. (2007)

CYP: soluble heme- CYP153 dependent cytochrome P450s
Diverse in structure, requires 3 components CYP-F-R Fiorentini et al. (2018)

Class VII CYP P450 Contains 1 gene consisting with 2 domains; a heme domain and a reductase domain Minerdi et al. (2015)

\section{$\mathrm{C}_{5}-\mathrm{C}_{16}$ alkanes, $\mathrm{C}_{10}-\mathrm{C}_{30}$} alkanes, limonene, cyclohexene, styrene, mediumand long-chain fatty acids van Beilen and Funhoff. (2007)

$\mathrm{C}_{14}-\mathrm{C}_{16}, \mathrm{C}_{24}, \mathrm{C}_{26}$ Minerdi et al. (2015)

\author{
$\mathrm{C}_{8}-\mathrm{C}_{16}$ alkanes, phytane Liu Cytochrome P450 alkane \\ et al. (2011), Wang and hydroxylase from \\ Shao. (2012), Liang et al. Alcanivorax dieselolei Liu \\ (2016a) \\ Medium- and long- chain \\ alkanes Minerdi et al. (2015) \\ et al. (2011) \\ CYP116B5 from \\ Acinetobacter radioresistens \\ Minerdi et al. (2015)
}

\begin{tabular}{|c|c|c|c|c|c|}
\hline $\begin{array}{l}\text { FMO: Soluble flavin- } \\
\text { binding } \\
\text { monooxygenase }\end{array}$ & AlmA & $\begin{array}{l}\text { Contains } 1 \text { gene } \\
\text { Throne-Holst et al. (2007) }\end{array}$ & $\begin{array}{l}\mathrm{C}_{14}-\mathrm{C}_{36} \text { alkanes Throne-Holst } \\
\text { et al. (2007), pristane } \\
\text { Throne-Holst et al. (2007), } \\
\text { Wang and Shao. (2014) }\end{array}$ & $\begin{array}{l}\mathrm{C}_{18}-\mathrm{C}_{36} \text { alkanes, pristane, } \\
\text { phytane Wang and Shao. } \\
\text { (2012) }\end{array}$ & $\begin{array}{l}\text { AlmA from Acinetobacter sp. } \\
\text { DSM } 17874 \text { Throne-Holst } \\
\text { et al. (2007) }\end{array}$ \\
\hline
\end{tabular}


TABLE 1 | (Continued) Organisation and properties of bacterial monooxygenases involved in aliphatic hydrocarbon degradation.

\begin{tabular}{|c|c|c|c|c|}
\hline Monooxygenase family & Description $^{a}$ & Substrate(s) & Inducer(s) & Example \\
\hline Dioxygenase & $\begin{array}{l}\text { Contains } 1 \text { gene, } \\
\text { requires } \mathrm{Cu}^{2+} \text { but not } \\
\text { NAD(P)H Maeng et al. } \\
(1996)\end{array}$ & $\begin{array}{l}\mathrm{C}_{10}-\mathrm{C}_{30} \text { alkanes, } \mathrm{C}_{12}-\mathrm{C}_{20} \\
\text { alkenes, amylbenzene and } \\
\text { tridecylbenzene Maeng et al. } \\
\text { (1996) }\end{array}$ & $\begin{array}{l}C_{10}-C_{30} \text { alkanes Maeng et al. } \\
\text { (1996), Sakai et al. (1996) }\end{array}$ & $\begin{array}{l}\text { Acinetobacter sp. M1 Sakai } \\
\text { et al. (1996) }\end{array}$ \\
\hline LadA & $\begin{array}{l}\text { Contains } 1 \text { gene } \\
\text { consisting of } 3 \text { domains; } \\
\text { a monooxygenase } \\
\text { domain, and } 2 \text { NAD(P)H } \\
\text { oxidation domains Feng } \\
\text { et al. (2007), Tourova } \\
\text { et al. (2016) }\end{array}$ & $\begin{array}{l}\mathrm{C}_{15}-\mathrm{C}_{36} \text { Feng et al. (2007), } \\
\text { Wang and Shao. (2013), Wang } \\
\text { and Shao. (2014), Tourova et al. } \\
\text { (2016) }\end{array}$ & $\begin{array}{l}\mathrm{C}_{22}-\mathrm{C}_{36} \text { alkanes Li et al. } \\
\text { (2008), Liu et al. (2011) }\end{array}$ & $\begin{array}{l}\text { LadA from Geobacillus } \\
\text { thermodenitrificans NG80-2 } \\
\text { Feng et al. (2007) }\end{array}$ \\
\hline
\end{tabular}

${ }^{a} \alpha, \beta, \gamma$, oxygenase subunits; $R$, reductase subunit; $C$, coupling protein; $F$, ferredoxin; $X$, protein of unknown function.

${ }^{b}$ This is tentatively inferred by the homology of the group 5 and group 6 SDIMOs to the group 4 alkene MOs.

involves the study of pure cultures of bacteria, database mining and/or metagenomics.

The identification of the monooxygenase responsible for aliphatic hydrocarbon oxidation is a natural first step in biosensor development for this class of compounds. The rationale for this is two-fold. Firstly, monooxygenase genes make better targets for bioprospecting (Holmes and Coleman, 2008) than the associated regulatory genes, which tend to be more diverse and thus more difficult to detect by PCR or sequence analysis. Secondly, in many cases, the inducers of aliphatic hydrocarbon degradation genes are not the alkanes or alkenes, but rather the downstream metabolites (alcohols, aldehydes, epoxides) (Kurth et al., 2008) and it is the monooxygenase enzymes that play the crucial role of converting the hydrocarbon of interest into the inducer molecule.

Monooxygenases are responsible for the oxidation of methyl or methylene groups in n-alkanes, which is the first step in the catabolism of $\mathrm{n}$-alkanes in all aerobic bacteria. The alcohols produced by this catalysis can then be oxidised into aldehydes or ketones, and then ultimately into fatty acids (Van Beilen et al., 2003; Kotani et al., 2006). Monooxygenases are of equal importance for alkene oxidation, with the resultant epoxides processed via a series of coenzyme $\mathrm{M}$ or glutathione-mediated reactions (Vlieg et al., 2000; Ensign, 2001; Mattes et al., 2010). It is not uncommon for one bacterial isolate to possess multiple monooxygenases of different types (Rojo, 2009), which may include both alkane and alkene-oxidising enzymes.

\subsection{Methods for Identifying the Presence of Monooxygenases in Bacterial Species}

Monooxygenase genes are most commonly identified in cultures obtained from enrichment and isolation on aliphatic hydrocarbons as the sole carbon source (Holmes and Coleman, 2008). Alternatively, these genes can be retrieved by metagenomic analysis, preferably using DNA from environments enriched in hydrocarbons (Musumeci et al., 2017; Gacesa et al., 2018), or by trawling pre-existing sequence data, which is now abundant due to the decreased costs of DNA sequencing. Monooxygenase homologues fall into distinct classes (Table 1), with known conserved sequence regions, and thus they can easily be identified purely based on sequence analysis in genomes or metagenomes, and functional approaches are not required at the gene discovery stage. The main classes of monooxygenases and their relevant properties are summarised in Table $\mathbf{1}$.

There is great interest in detecting and recovering new monooxygenases, due to their interesting catalytic properties and also due to their linkage to useful regulators for biosensor construction. Nested PCR with degenerate primers enabled recovery of novel soluble di-iron monooxygenases (SDIMO) from soils, sediments, and enrichment cultures, and was also useful for identifying interesting isolates which contained multiple SDIMO genes (Coleman et al., 2006). Other PCR approaches have been invaluable for screening isolate collections for AlkB type monooxygenases (Smits et al., 1999; Van Beilen et al., 2003). Metaproteomics approaches have been used to identify novel alkene monooxygenases in enrichments from vinyl-chloride contaminated groundwater (Chuang et al., 2010), and to identify archaeal ammonia monooxygenases (a coppercontaining membrane monooxygenase, CuMMO) in marine samples (Morris et al., 2010). Novel CuMMOs have also been isolated from an oilsands tailing pond using stable isotope probing and qPCR methods (Rochman et al., 2020).

\subsection{Functional Characterisation of Monooxygenases}

Once a novel target gene has been identified, it is most important for biosensor development to confirm that the monooxygenase genes are indeed inducible by hydrocarbons (or metabolites thereof) (Vogne et al., 2010). Determining other parameters such as substrate range and kinetics are also very important for related applications like bioremediation. Techniques used to confirm the function of novel monooxygenases may include biochemical assays (resting cells, cell extracts etc.), omics approaches (e.g., transcriptomics, proteomics), or genetic methods (knockouts, knockdowns, heterologous expression).

Alkane-degrading bacterial species are diverse and some are well-characterised, with Actinobacteria such as Corynebacterium, Mycobacterium, Nocardia and Rhodococcus dominating when gaseous substrates are used (Shennan, 2006) and 
TABLE 2 | Classification and quantification of monooxygenase homologues and related publications in public databases.

\begin{tabular}{|c|c|c|c|c|c|}
\hline \multirow{2}{*}{$\begin{array}{l}\text { Representative enzyme subunit } \\
\text { used for BLAST } \\
\text { analysis }\end{array}$} & \multicolumn{3}{|c|}{ Monooxygenase homologues } & \multicolumn{2}{|c|}{ Related publications } \\
\hline & Uniprot ID & GenBank ID & No. of homologues ${ }^{a}$ & Scopus keyword(s) & No. of publications \\
\hline XamoA, Xanthobacter Py2 & O87082 & AJ006979.1 & 951 & "Propene monooxygenase" & 5 \\
\hline MmoX, Methylococcus capsulatus Bath & P22869 & M90050.3 & 810 & "Soluble methane monooxygenase" & 426 \\
\hline EtnC, M. chubuense NBB4 & D2K2E0 & GU174752.1 & 37 & "Ethene monooxygenase" & 6 \\
\hline PrmA, Gordonia TY5 & Q768T5 & AB112920 & 1,551 & "Propane monooxygenase" & 38 \\
\hline PrmA, Mycobacterium TY-6 & Q08KF2 & AB250938 & 959 & & \\
\hline PmoC1, Methylococcus capsulatus Bath & Q603F1 & AE017282 & 1,103 & "Particulate methane monooxygenase" & 500 \\
\hline AlkB, P. putida Gpo1 & P12691 & AJ245436 & 5,010 & "AlkB" & 1855 \\
\hline CYP153, Alcanivorax dieselolei & D0Q1H3 & GQ980250 & 5,046 & "CYP153” & 67 \\
\hline CYP116B5, A. radioresistens S13 & G9BWN9 & HQ685898 & 2,787 & "CYP116B5" & 2 \\
\hline AlmA, Acinetobacter sp. & AOA2U9IB23 & MH357335 & 5,060 & "AlmA" AND "monooxygenase" & 14 \\
\hline LadA, Burkholderia sp. & A0A095EJX9 & CP007785 & 4,798 & "LadA" AND "monooxygenase" & 14 \\
\hline AlkMa, Acinetobacter sp. M1 & Q9AQK2 & AB049410 & 5,012 & "AlkMa" & 5 \\
\hline
\end{tabular}

${ }^{a}$ Homologues were defined here as BLAST matches with $>40 \%$ amino acid identity.

Proteobacteria such as Pseudomonas, Acinetobacter, and Alcanivorax more typical when liquid substrates are used (Nie et al., 2014a). The best-characterised alkane monooxygenase is AlkB from P. putida GPo1, isolated on hexane, which can oxidise $\mathrm{C}_{5}-\mathrm{C}_{9}$ n-alkanes (Baptist et al., 1963; van Beilen et al., 1994). AlkB requires accessory proteins (AlkG, AlkT) to deliver electrons from NADH to enable the activation of molecular oxygen. Many other classes of monooxygenases can also attack alkanes, including iron, flavin, and copper-requiring enzymes (Table 1, also see reference Moreno and Rojo, 2017). The gene arrangements of a selection of characterised alkane monooxygenases can be seen in Figure 2.

There are fewer examples of alkene-oxidising enzymes (Table 1), with the two best-studied systems being the propene monooxygenases of Rhodococcus rhodochrous (Gallagher et al., 1997; Gallagher et al., 1998; Smith et al., 1999) and Xanthobacter Py2 (Ginkel, 1987; Ginkel et al., 1987; Small and Ensign, 1997; Champreda et al., 2004). Despite having the same primary substrate, these two enzymes are diverse in both sequence and structure; the former is encoded by four genes encoding three enzyme subunits (Smith et al., 1999) while the latter is a six gene, four component system (Small and Ensign, 1997; McCarl et al., 2018). Major advances since the alkene monooxygenases were last reviewed (Ensign, 2001; Shennan, 2006) include the identification, characterisation, and heterologous expression of the genes encoding the ethene monooxygenases (EtnABCD) found in Nocardioides and Mycobacterium spp. (Coleman and Spain, 2003b; Mattes et al., 2005; Coleman et al., 2011a; McCarl et al., 2018) and the investigation of these enzymes as biocatalysts for epoxide synthesis (Owens et al., 2009; Cheung et al., 2013).

The number of homologs in databases and the number of publications relevant to each representative monooxygenase are shown in Table 2. These numbers reflect the sheer volume of candidate enzymes that have been identified to date; the research at this early stage of the biosensor development framework is abundant. The relationship between monooxygenase genes and hosts is complex and it is likely that the corresponding genes have been subject to extensive lateral gene transfer (Coleman and
Spain, 2003a; Das et al., 2015; Minerdi et al., 2015; Liang et al., 2016a; Khadka et al., 2018). The SDIMO and CuMMO type monooxygenases have quite restricted distribution compared to the AlkB and CYP153 enzymes; the latter are common in the genomes of environmental bacteria (Nie et al., 2014b).

\section{IDENTIFICATION AND CHARACTERISATION OF REGULATORY SYSTEMS \\ 4.1 Initial Identification of Regulatory System Components}

Important questions to be answered for newly discovered regulatory systems include: What are the inducers? Is it a onecomponent or two-component system? Are there additional layers of control apart from the hydrocarbon (or hydrocarbon metabolite) inducer? The investigation typically begins with bioinformatics, via identification of regulator gene(s), and the cognate promoter and operator sequences. Regulator genes are usually identified based on their proximity to the monooxygenase genes, and via sequence similarities to known transcription factors. Promoters can be identified on the basis of consensus sequences (e.g., -35 and -10 motifs) and their location upstream of the monooxygenase genes. Operators typically have an inverted repeat structure and will be located proximal to the promoter, either upstream (activators) or downstream (repressors) (Browning and Busby, 2016).

Pull-down assays offer an alternative method of identifying regulator proteins (Ji et al., 2019), in which a DNA containing the promoter sequence is immobilized on beads, cell extracts are washed over the beads, then proteins bound to the promoter sequence can be identified by mass spectrometry. This method allows regulatory proteins to be identified independent of bioinformatic predictions, but it does require that the promoter sequence is known, and it may be complicated by competitive binding of multiple proteins to the promoter; this may cause regulators that bind with lower 
affinity to be overlooked. Other protein-DNA binding assays useful for identifying promoter/regulator pairs are electrophoretic mobility shift assays (EMSA) and DNase footprinting; in the former case, regulators are detected by their retardation of the gel mobility of a DNA containing the promoter sequence, while in the latter case, they are found by their ability to protect the promoter sequence from DNase digestion (Read et al., 2009).

Vogne et al. (2010) describe five criteria that should be addressed in the characterisation of catabolic regulatory factors, summarised below. In the case of alkane regulatory systems, these criteria have only been met in a handful of cases.

(1) There must be evidence for involvement of the regulator in gene expression.

(2) The genes being controlled must be identified.

(3) The promoter elements associated with the regulatory protein must be identified.

(4) The expression of the regulator gene itself must be investigated.

(5) The inducer compound and its relationship with the regulator must be understood.

\subsection{Experimental Methods for Characterisation of Regulatory Systems}

Two general approaches can be used to confirm the function of regulatory system elements; either untargeted methods e.g., proteomics and transcriptomics, or targeted methods e.g., heterologous expression, knock-ins, knockouts, knockdowns, pull-downs, gel shift assays, or footprinting. These approaches are described below.

Transcriptomics gives information about the expression patterns of different genes under different conditions. If exposure to a suspected inducer leads to higher expression levels of a particular gene, this provides strong preliminary evidence that the enzyme encoded by that gene is part of a metabolic pathway controlled by that inducer; searching upstream from the induced gene then allows discovery of the likely promoter. Alternatively, promoters can be found via transcriptomics via pinpointing intergenic regions which are not themselves transcribed. Finally, transcriptomics data can provide clues about the control of the regulatory genes themselves, such as whether these are constitutively expressed, or part of positive or negative feedback loops.

Heterologous expression can be used to confirm the role of regulatory proteins, e.g., by cloning the regulator gene and its cognate promoter and operator elements into a plasmid and adding a reporter gene downstream of the promoter. Exposure to the correct inducer will result in expression of the reporter gene if the combination of regulatory protein, promoter and operator sequences is correct. While a good starting point, there are limitations to this method, as follows; there may be multiple regulatory proteins required to evoke the desired response, the regulatory proteins might be hard to express in a heterologous host due to codon usage issues or due to strain-specific genes required for regulator protein function e.g. chaperones, the structure and type of plasmid used may unexpectedly impact the outcomes due to effects arising from copy number, gene orientation, or transcription read-through.

Gene knock-in methods are another useful targeted approach to testing hypotheses about regulatory systems. This involves integrating a reporter gene downstream of the promoter in the genome of the native organism, either in front of the metabolic genes, or replacing them. Exposure to the correct inducer should yield expression of the reporter gene. Knock-in methods have several advantages over heterologous expression in plasmids, most notably that they sidestep problems arising from codon usage, plasmid copy number, and altered genomic context. The major disadvantage of gene knock-ins is that they may be technically more difficult to generate, depending on the host organism.

Gene knockouts can also be used to interrogate the components of hydrocarbon regulatory systems. Knocking out the putative regulatory gene can be done via homologous recombination (usually replacing the regulator with a resistance gene) or via CRISPR-Cas-based methods; the latter are preferable due to the increased specificity and higher frequency of deletion mutants obtainable, but the choice here may be limited by the genetic tools available in the host species of interest. The impact of the knockout on the host organism's phenotype can be readily tested, e.g., its ability to oxidise hydrocarbons. For repressors, a knockout should yield a constitutive hydrocarbon-oxidising phenotype, while for activators, a decreased or abolished ability to oxidize hydrocarbons would be expected.

Gene knockdowns enable the regulatory gene to be turned down or off temporarily via technologies such as interfering RNA (RNAi) (Hannon, 2002; Kim and Rossi, 2018) or dead Cas9 (dCas9) proteins (Dong et al., 2018). The overall strategy here is similar to the knock-outs described above, with the impact tested either via measuring hydrocarbon oxidation in the resultant recombinants or via a reporter gene if this has been integrated in place of the metabolic genes. An advantage of the knock-down approach is that it can be used to test inactivation of regulators of essential genes, since the bacteria can be grown first, then the knock-down activated, e.g., testing methane monooxygenase regulators in obligate methanotrophs.

\section{REGULATORY SYSTEMS FOR ALKANE MONOOXYGENASES}

The most well-studied alkane monooxygenase regulatory systems are those associated with the AlkB and CYP153 monooxygenases, but there is also information available on the regulators of AlkB2, AlkM, AlmA, AlkW, BmoXYBZDC, PrmABCD and SmoABCD. Taken together, these represent nine regulatory systems across seven species that have been experimentally characterised. If putative regulatory proteins identified by sequence analysis only are included, this count increases to 19 systems (Tables $3,4)$. Details of the elements of these systems and their functions are described in the sections below. The positioning of a selection of regulatory genes relative to the relevant monooxygenase gene cluster can be seen in Figure 2. 
TABLE 3 | Sequences of characterised alkane monooxygenase promoters.

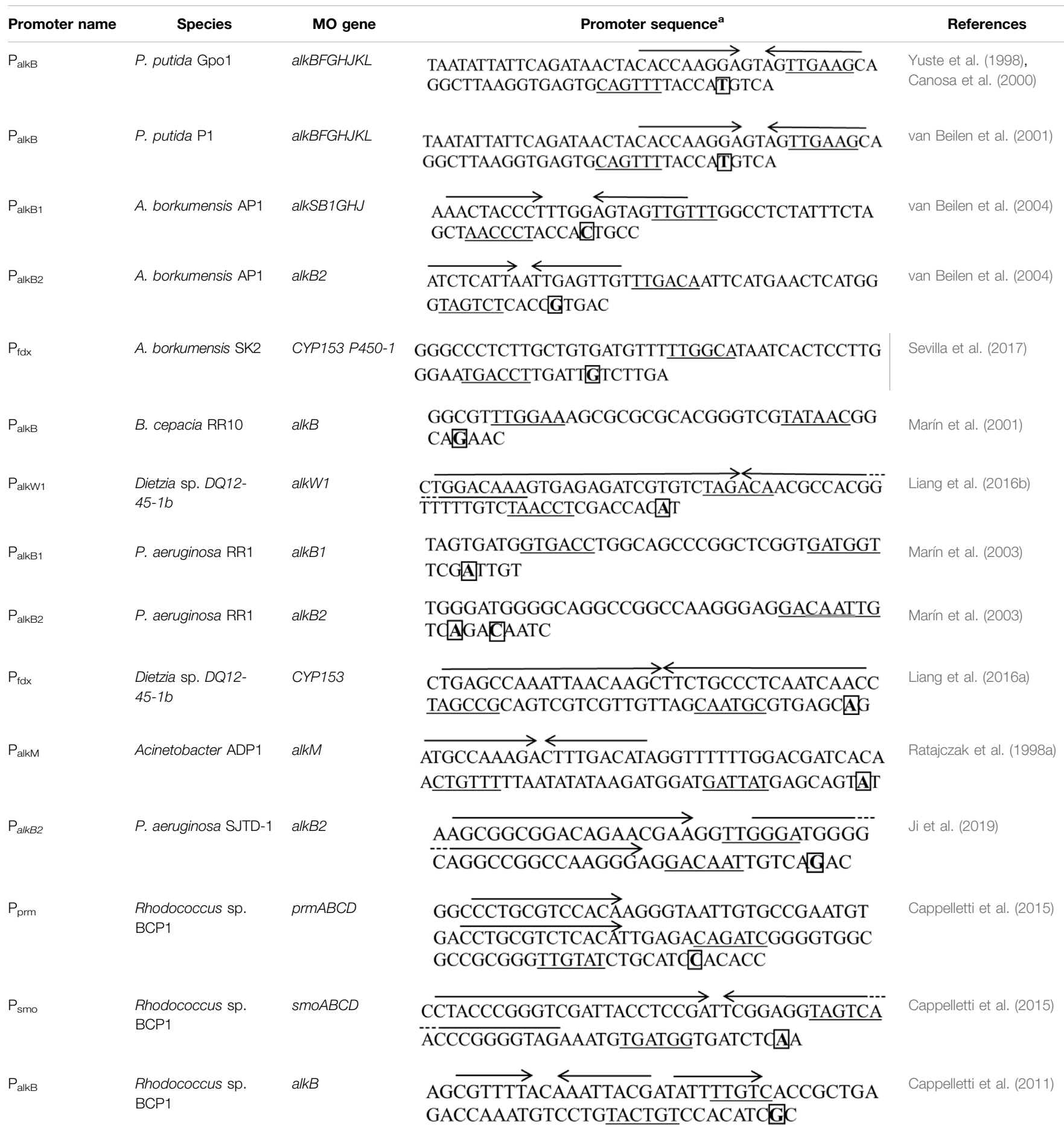

\footnotetext{
${ }^{a}$ The -35 and -10 motifs are underlined, transcription start points are in bold, and inverted repeats are shown with arrows. All of these elements were identified in prior studies except in the case of $P_{a l k B 1}$ of $\mathrm{A}$. borkumensis $A P 1$, where we have tentatively identified the $-35,-10$, and start point as part of this study.
}

It is important to note that the well-characterised alkane regulatory systems represent only a small fraction of the total diversity, and comparisons between these indicate the limitations in extrapolating conclusions from one system to another. The bias in research towards AlkB and CYP153 has left large knowledge gaps for other systems, and a further limitation is that more work has been focused on the monooxygenases rather than their regulatory systems-this is a major bottleneck in the 
TABLE 4 | Summary of identified and/or characterised monooxygenase regulatory systems from literature.

\begin{tabular}{|c|c|c|c|c|c|c|c|c|}
\hline $\begin{array}{l}\text { Regulator } \\
\text { family }\end{array}$ & $\begin{array}{c}\text { Nature } \\
\text { of } \\
\text { regulator }\end{array}$ & $\begin{array}{l}\text { Regulator } \\
\text { gene }\end{array}$ & $\begin{array}{l}\text { Cognate } \\
\text { promoter }^{a}\end{array}$ & $\begin{array}{l}\text { Bacterial } \\
\text { strain }\end{array}$ & Monooxygenase & Inducers & $\begin{array}{l}\text { Evidence } \\
\text { for regulator } \\
\text { function }\end{array}$ & References \\
\hline \multirow[t]{4}{*}{ LuxR/MalT } & Activator & AlkS & $P_{\text {alkB }}$ & P. putida GPo1 & $\begin{array}{l}\text { alkBFGHJKL } \\
\text { alkST }\end{array}$ & $\begin{array}{l}\mathrm{C}_{6}-\mathrm{C}_{10} \\
\text { n-alkanes }\end{array}$ & $\begin{array}{l}\text { Heterologous } \\
\text { expression in E.coli }\end{array}$ & $\begin{array}{l}\text { Sticher et al. (1997), } \\
\text { Panke et al. (1999), } \\
\text { Canosa et al. (2000), } \\
\text { van Beilen et al. (2001) }\end{array}$ \\
\hline & & & $\mathrm{P}_{\text {alkB }}$ & P. putida P1 & $\begin{array}{l}\text { alkBFGHJKL } \\
\text { alkST }\end{array}$ & & $\begin{array}{l}\text { Inferred from results } \\
\text { with GPo1 }\end{array}$ & van Beilen et al. (2001) \\
\hline & Activator & & $\mathrm{P}_{\text {alkB1 }}$ & $\begin{array}{l}\text { A. } \\
\text { borkumensis SK2 }\end{array}$ & alkSB1GHJ & $\begin{array}{l}\mathrm{C}_{5}-\mathrm{C}_{12} \\
\text { n-alkanes }\end{array}$ & Sequence analysis only & Schneiker et al. (2006) \\
\hline & & & $P_{\text {alkB1 }}$ & $\begin{array}{l}\text { A. } \\
\text { borkumensis AP1 }\end{array}$ & alkSB1GHJ & $\begin{array}{l}\mathrm{C}_{5}-\mathrm{C}_{12} \\
\text { n-alkanes }\end{array}$ & $\begin{array}{l}\text { S1 nuclease protection } \\
\text { assay; lacZ } \\
\text { transcriptional fusion }\end{array}$ & van Beilen et al. (2004) \\
\hline \multirow[t]{7}{*}{ AraC/Xyls } & Activator & cypR & ${ }^{\star} \mathrm{P}_{\mathrm{fdx}}$ & $\begin{array}{l}\text { A. } \\
\text { borkumensis SK2 }\end{array}$ & CYP153 & $\begin{array}{l}\mathrm{C}_{8}-\mathrm{C}_{18} \\
\text { n-alkanes }\end{array}$ & $\begin{array}{l}\text { Promoter-GFP } \\
\text { transcriptional fusions; } \\
\text { gene-inactivation }\end{array}$ & $\begin{array}{l}\text { Schneiker et al. (2006), } \\
\text { Sevilla et al. (2017) }\end{array}$ \\
\hline & Activator & & ${ }^{*} \mathrm{P}_{\mathrm{fdx}}$ & $\begin{array}{l}\text { Dietzia sp. DQ12- } \\
45-b 1\end{array}$ & CYP153 & $\begin{array}{l}\mathrm{C}_{8}-\mathrm{C}_{14} \\
\text { n-alkanes }\end{array}$ & $\begin{array}{l}\text { Promoter-lacZ fusion } \\
\text { assays; gene- } \\
\text { inactivation; RACE } \\
\text { analysis }\end{array}$ & Liang et al. (2016b) \\
\hline & Activator & alkR & ${ }^{*} \mathrm{P}_{\text {alkM }}$ & $\begin{array}{l}\text { Acinetobacter sp. } \\
\text { ADP1 }\end{array}$ & alkM & $\begin{array}{l}\mathrm{C}_{7}-\mathrm{C}_{18} \\
\text { n-alkanes }\end{array}$ & $\begin{array}{l}\text { Gene-inactivation; lacZ } \\
\text { chromosomal fusions }\end{array}$ & $\begin{array}{l}\text { Ratajczak et al. } \\
\text { (1998a), Ratajczak } \\
\text { et al. (1998b) }\end{array}$ \\
\hline & Activator & alkRa & ${ }^{*} \mathrm{P}_{\text {alkMa }}$ & $\begin{array}{l}\text { Acinetobacter } \\
\text { sp. M1 }\end{array}$ & alkMa & $\begin{array}{l}>\mathrm{C}_{22} \\
\text { n-alkanes }\end{array}$ & Sequence analysis only & Tani et al. (2000) \\
\hline & Activator & $a l k R b$ & ${ }^{*} \mathrm{P}_{\mathrm{alkMb}}$ & $\begin{array}{l}\text { Acinetobacter } \\
\text { sp. M1 }\end{array}$ & alkMb & $\begin{array}{l}\mathrm{C}_{16}-\mathrm{C}_{22} \\
\text { n-alkanes }\end{array}$ & Sequence analysis only & Tani et al. (2000) \\
\hline & - & Orf1 & - & A. dieselolei B5 & alkB2 & $\begin{array}{l}\mathrm{C}_{12}-\mathrm{C}_{26} \\
\text { n-alkanes }\end{array}$ & Sequence analysis only & Liu et al. (2011) \\
\hline & - & Orf3 & - & A. dieselolei B5 & CYP153 & $\begin{array}{l}\mathrm{C}_{8}-\mathrm{C}_{16} \\
\text { n-alkanes }\end{array}$ & Sequence analysis only & Liu et al. (2011) \\
\hline None & Repressor & almR & - & A. dieselolei B5 & almA & $\begin{array}{l}\mathrm{C}_{22}-\mathrm{C}_{30+} \\
\text { n-alkanes }\end{array}$ & $\begin{array}{l}\text { Gene-inactivation } \\
\text { experiments }\end{array}$ & $\begin{array}{l}\text { Liu et al. (2011), Wang } \\
\text { and Shao (2014) }\end{array}$ \\
\hline \multirow[t]{2}{*}{ TetR } & Repressor & alkX & $\mathrm{P}_{\mathrm{alkW} 1}$ & $\begin{array}{l}\text { Dietzia sp. DQ12- } \\
45-b 1\end{array}$ & alkW1X & $\begin{array}{l}\mathrm{C}_{10}-\mathrm{C}_{24} \\
\text { fatty acids }\end{array}$ & $\begin{array}{l}\text { Dnase I footprinting } \\
\text { assay, EMSA }\end{array}$ & Liang et al. (2016a) \\
\hline & - & Orf10 & - & $\begin{array}{l}\text { A. hongdengensis } \\
\text { A-11-3 }\end{array}$ & alkB1 & $\begin{array}{l}\mathrm{C}_{12}-\mathrm{C}_{24} \\
\text { n-alkanes }\end{array}$ & Sequence analysis only & Wang and Shao (2012) \\
\hline \multirow[t]{3}{*}{ GntR } & Repressor & gntR & $\mathrm{P}_{\text {alkB2 }}$ & $\begin{array}{l}\text { A. } \\
\text { borkumensis SK2 }\end{array}$ & alkB2 & $\begin{array}{l}\mathrm{C}_{8}-\mathrm{C}_{16} \\
\text { n-alkanes }\end{array}$ & Sequence analysis only & $\begin{array}{l}\text { van Beilen et al. (2004), } \\
\text { Schneiker et al. (2006) }\end{array}$ \\
\hline & - & Orf2O & - & $\begin{array}{l}\text { A. hongdengensis } \\
\text { A-11-3 }\end{array}$ & alkB2 & $\begin{array}{l}\mathrm{C}_{12}-\mathrm{C}_{24} \\
\text { n-alkanes }\end{array}$ & Sequence analysis only & Wang and Shao (2012) \\
\hline & - & PA1526 & $\mathrm{P}_{\text {alkB2 }}$ & $\begin{array}{l}P . \text { aeruginosa } \\
R R 1 / P A O 1\end{array}$ & alkB2 & $\begin{array}{l}\mathrm{C}_{12}-\mathrm{C}_{20} \\
\text { n-alkanes }\end{array}$ & Sequence analysis only & $\begin{array}{l}\text { Marín et al. (2003), } \\
\text { Smits et al. (2003) }\end{array}$ \\
\hline LysR & Repressor & CrgA & $\mathrm{P}_{\mathrm{alkB2}}$ & $\begin{array}{l}\text { P. aeruginosa } \\
\text { SJTD-1 }\end{array}$ & alkB2 & $\begin{array}{l}\mathrm{C}_{14}-\mathrm{C}_{20} \\
\text { n-alkanes }\end{array}$ & $\begin{array}{l}\text { Gene inactivation; } \\
\text { EMSA; DNase I } \\
\text { footprinting; promoter- } \\
\text { GFP plasmid assays }\end{array}$ & Ji et al. (2019) \\
\hline$\sigma^{54}-$ dependent & Activator & $b m o R$ & $\mathrm{P}_{\mathrm{bmo}}$ & T. butanivorans & bmoXYBZDC & $\begin{array}{l}\mathrm{C}_{2}-\mathrm{C}_{8} \\
\text { n-alkanols }\end{array}$ & $\begin{array}{l}\text { Gene-inactivation; } \\
\text { promoter-lacZ fusion } \\
\text { assays }\end{array}$ & Kurth et al. (2008) \\
\hline \multirow[t]{4}{*}{ Fis } & - & - & ${ }^{*} \mathrm{P}_{\mathrm{prm}}$ & $\begin{array}{l}\text { Rhodococcus sp. } \\
\text { BCP1 }\end{array}$ & prmABCD & $\begin{array}{l}\mathrm{C}_{3}-\mathrm{C}_{4} \\
\text { n-alkanes }\end{array}$ & Sequence analysis only & Cappelletti et al. (2015) \\
\hline & - & - & ${ }^{*} \mathrm{P}_{\mathrm{prm}}$ & $\begin{array}{l}\text { Rhodococcus sp. } \\
\text { RHA1 }\end{array}$ & prmABCD & - & Sequence analysis only & Cappelletti et al. (2015) \\
\hline & - & - & ${ }^{*} \mathrm{P}_{\mathrm{prm}}$ & $\begin{array}{l}\text { Rhodococcus } \\
\text { opacus PD630 }\end{array}$ & prmABCD & - & Sequence analysis only & Cappelletti et al. (2015) \\
\hline & - & - & ${ }^{*} \mathrm{P}_{\mathrm{prm}}$ & $\begin{array}{l}\text { M. smegmatis } \\
\text { MC2 } 155\end{array}$ & prmABCD & - & Sequence analysis only & Cappelletti et al. (2015) \\
\hline \multirow[t]{2}{*}{$\begin{array}{l}\text { LuxR + NarQ-like } \\
\text { sensor kinase }\end{array}$} & - & - & ${ }^{*} \mathrm{P}_{\mathrm{smo}}$ & $\begin{array}{l}\text { Rhodococcus sp. } \\
\text { strain BCP1 }\end{array}$ & $s m o A B C D$ & $\begin{array}{l}\mathrm{C}_{1}-\mathrm{C}_{7} \\
\text { n-alkanes }\end{array}$ & Sequence analysis only & Cappelletti et al. (2015) \\
\hline & - & - & ${ }^{*} P_{\text {smo }}$ & $\begin{array}{l}\text { M. chubuense } \\
\text { NBB4 }\end{array}$ & smoABCD & - & Sequence analysis only & $\begin{array}{l}\text { Coleman et al. } \\
\text { (2011a), Cappelletti } \\
\text { et al. (2015) }\end{array}$ \\
\hline
\end{tabular}

${ }^{a}$ Asterisks here indicate that the promoter has not been named in previous reports. Promoter names assigned here are based on previous naming conventions. 
development of alkane biosensors. A better understanding of the regulation of alkane oxidation systems is needed, via following the characterisation criteria (Vogne et al., 2010) outlined in the previous section.

\subsection{Promoters and Operator Sequences}

Identifying promoter and operator elements is an essential part of understanding the mechanism of action of transcription factors. Sigma factors are key players in transcriptional initiation and in bacteria $\sigma^{70}$ and $\sigma^{54}$ are the two dominant subclasses. Each recognizes and binds to specific promoter elements that allows for the recruitment and correct coordination of RNA polymerase. Promoters can be identified by locating either the $\sigma^{70}$ promoter elements at the -10 and -35 positions relative to the transcriptional start site (Paget and Helmann, 2003), or the $\sigma^{54}$ promoter elements at the -12 and -24 positions (Buck and Cannon, 1992; Francke et al., 2011). The known promoters and operator sequences associated with alkane monooxygenases are summarised in Table 3. The degree of characterisation of these elements varies across species and there is much work still to be done to understand the details of promoter-protein relationships in the hydrocarbon metabolism regulators.

The operator elements associated with monooxygenase promoters consist of repeat sequences adjacent to the -35 site. Nearly all the monooxygenase promoter sequences identified in literature show such repeats (Table 3). Sometimes these sequences are imperfect direct repeats, like the sequence enabling CrgA binding in the alkB2 promoter of $P$. aeruginosa SJTD-1 (Jiménez et al., 2019). In other cases, these are inverted repeats, such as that found between alkR and alkM in Acinetobacter sp. ADP1; interestingly in this case, the regulator protein is in the AraC/XylS family, which are normally associated with direct repeats (Ratajczak et al., 1998a).

The identification of operator sequences provides crucial insights into the function of regulatory systems. For example, the operators recognised by the AlkS regulator in P.putida Gpo1 are found upstream of both the monooxygenase promoter $\mathrm{P}_{\mathrm{alkB}}$ and also the AlkS promoter $\mathrm{P}_{\text {alks2 }}$ (Canosa et al., 2000), indicating a positive feedback loop in this system. The inverted repeat sequence recognised by AlkS is highly homologous to other operators controlled by LuxR-family proteins (Fuqua et al., 1996). Gene expression from the $\mathrm{P}_{\text {alkB }}$ promoter drops to negligible levels when the operator is removed (Canosa et al., 2000), confirming that AlkS is an activator protein rather than a repressor. The function of the AlkS operator was confirmed in an assay using a recombinant E. coli containing a chromosomal $x y l E$ reporter under the control of alkS and $P_{\text {alkB }}$ (van Beilen et al., 2001). A reduction in expression of $x y l E$ was seen when the operator sequences were supplemented on a plasmid, consistent with competition for AlkS between the plasmid and chromosomal sequences (van Beilen et al., 2001).

Although the presence of repeat sequences near a promoter is indicative of an operator, this needs to be experimentally validated, even in cases where homology to characterised operators is high. The promoters of both alkB1 and alkB2 in A.borkumensis contain homologs of the AlkS operator from P.putida Gpo1. While a transcriptional fusion of $P_{\text {alkB1}}$ to lacZ was responsive to alkanes, a similar fusion to $P_{\text {alkB2 }}$ while not (van Beilen et al., 2004), implying that the putative AlkS binding site upstream of alkB2 is not functional, despite its strong homology to functional operator sequences.

\subsection{Understanding Expression of Regulatory Genes, and the Inducer-Protein Relationship}

Most alkane monooxygenase regulators are activator proteins (Moreno and Rojo, 2019), induced by the alkane directly, e.g. AlkS in P. putida Gpol (Kok et al., 1989), or induced by a downstream metabolite, e.g. BmoR in T. butanivorans (Kurth et al., 2008). The latter systems depend on the monooxygenase having a non-zero level of expression in the "switched off" state, so the inducer can be made from the alkane. Most alkane regulatory systems display self-regulation, such as AlkS in $P$. putida Gpo1. In the absence of alkanes, alkS is expressed from $\mathrm{P}_{\mathrm{alkS} 1}$, and expression levels are kept low by a self-repressive effect of AlkS on $\mathrm{P}_{\text {alkS1 }}$. Upon the addition of alkanes, AlkS activates the adjacent $\mathrm{P}_{\text {alkS2 }}$ promoter, driving high levels of AlkS expression in a positive feedback loop, and also repressing expression from $\mathrm{P}_{\text {alkS1 }}$ (Canosa et al., 2000). In Dietzia sp. DQ12-45-b1, fatty acids reduce AlkX repression on the alkW1 promoter in a positive feedback loop (Liang et al., 2016b). Meanwhile, in A. borkumensis AP1, the regulatory gene alkS is expressed constitutively, independent of the presence of alkanes (van Beilen et al., 2004).

Species that contain multiple monooxygenases complicate the understanding of induction processes due to possible overlaps between the inducer range and substrate range of the monooxygenases. For example, in $A$. dieselolei B5, the CYP153 is expressed in the presence of $\mathrm{C}_{8}-\mathrm{C}_{16}$ n-alkanes, the $\operatorname{alm} A$ monooxygenase is induced by $\mathrm{C}_{22}-\mathrm{C}_{36} \mathrm{n}$-alkanes, both alkB1 and alkB2 monooxygenases are induced by $\mathrm{C}_{12}-\mathrm{C}_{26}$ $\mathrm{n}$-alkanes, and $\operatorname{alkB1}$ and $\operatorname{alm} A$ expression can also be upregulated by the branched alkanes pristane and phytane (Liu et al., 2011). An overlapping substrate range for two AlkBtype monooxygenases is also seen in A. borkumensis AP1, where $\mathrm{C}_{10}, \mathrm{C}_{12}, \mathrm{C}_{14}$ and $\mathrm{C}_{16} n$-alkanes induce both alkB1 and alkB2 (van Beilen et al., 2004). The correlations of inducers to regulators can be teased apart via the generation of deletion mutants, but this is not always straightforward, e.g., in situations where one monooxygenase can generate the metabolite inducer for another.

\subsection{Alkene/Alkane Specificity}

The AlkM monooxygenase of A. baylyi ADP1 is an alkaneinduced system activated by the AlkR regulator (Ratajczak et al., 1998b). However, AlkR also responds strongly to the alkene octadecene, which is second only to octadecane in its strength as an inducer (Zhang et al., 2012b). The shorter alkene dodecene is also a very effective inducer for the ADP1 AlkR regulator. These findings emphasise the fact that the size of the 
inducer molecule is more important than the presence of a double bond in determining whether it will act as an effective inducer. It is likely that other "alkane-inducible" regulators also respond to similarly-sized alkenes, regardless of the substrate range of the cognate monooxygenase. This is part of the relationship between inducer compounds and regulatory proteins that should be explored further.

\subsection{Structures of Alkane Regulators}

Transcriptional regulators have two protein domains-a DNAbinding domain, and a sensing domain. DNA-binding domains are readily identifiable because they contain conserved motifs, such as helix-turn-helix and zinc finger domains (Harrison, 1991), while sensing domains are more diverse and hard to identify based solely on bioinformatics. Diverse families of transcription factors have been recruited as alkane sensors, including proteins from the LuxR, AraC, TetR, GntR, LysR and Fis families (Table 4). Each of these families have unique organisation and features, e.g., LuxR and AraC family proteins have the DNA-binding motif at the C-terminus, while GntR and TetR family proteins have the DNAbinding domain at the N-terminus (Gallegos et al., 1997; Schrijver et al., 1999; Santos et al., 2012; Cuthbertson and Nodwell, 2013). There is also great diversity within families, e.g., the AlkR and CypR regulators of Acinetobacter sp. ADP1 and Dietzia sp. DQ12-45-b1 have sequence motifs common to AraC/XylS family proteins, but the overall sequence identity between these two proteins is only 26\% (Liang et al., 2016a).

The AraC/XylS regulators also have different inducer ranges even within the same species. This is particularly noticeable when comparing the alkR, alkRa and alkRb candidates from Acinetobacter sp. APD1 and M1. There are three distinct inducer ranges for these monooxygenases, suggesting no such pattern exists at the regulatory family level. In some cases, however, there are similarities in the inducer range of each family of regulators. The inducers for the characterised LuxR-MalT family regulators are highly consistent even across bacterial species. This could be another way to infer characteristics of uncharacterised regulatory systems. For example, the regulator Orf3 linked to the CYP153 cluster from $A$. dieselolei $\mathrm{B} 5$ has an overlapping inducer range to $c y p R$ from both $A$. borkumensis SK2 and Dietzia sp. DQ12-45-b1 suggesting it might have a similar mechanism of action.

There is very little research on the protein structure of alkane regulators, and how this determines the relationships with inducers. Only one crystal structure is available, for AlkX from Dietzia sp. DQ12-45-1b (Liang, 2017). This protein appears to represent a new sub-family of TetR regulators (Liang, 2017). The AlkX binding pocket can accommodate fatty acids, which supports previous data showing that $\mathrm{C}_{10^{-}}$ $\mathrm{C}_{24}$ fatty acids interfere with DNA binding of this regulator (Liang et al., 2016b); this feature was confirmed by the finding that AlkX crystals made via heterologous expression in E. coli contained host-derived palmitic acid in the substrate-binding pocket. The operator associated with AlkX is longer than typical sequences, consistent with AlkX binding as a dimer or pair of dimers. The crystal structure of AlkX gives insight into the inducer range, with the arrangement of hydrophobic and hydrophilic residues in the binding pocket suggesting a minimum chain length of fatty acid required to remain in the pocket.

\subsection{Differences in Regulation of AlkB-Like Monooxygenases}

Given the diversity in sequences and bacterial hosts of AlkB monooxygenases (Nie et al., 2014a), it is not surprising that the regulation of these systems is also diverse. In most cases, the $n$-alkane is the inducer, however in at least one case (Rhodoccocus sp. BCP1), an alcohol can also act as inducer (Cappelletti et al., 2015). Comparison of the regulation of the ADP1 and GPo1 AlkM and AlkB enzymes is informative (note that the ADP1 AlkM monooxygenase is a homolog of AlkB, at $41 \%$ amino acid identity). Regulation of AlkM in ADP1 is simple, and occurs solely via the AlkR protein, which is constitutively expressed at low levels in the cell, and activates alkM expression in the presence of long-chain alkanes (Ratajczak et al., 1998a). In contrast, the situation in $P$. putida GPol is more complex (Yuste et al., 1998), with the alkBFGHJKL cluster controlled by the AlkS regulator via a positive feedback loop, as described in a previous section. The regulator AlkS is partly responsible for limitations on the hydrocarbon substrate range of $P$. putida GPo1, since the range of inducers that it recognises is narrower than the oxidation range of AlkB.

Differences in the regulation of AlkB-type monooxygenases have implications for future biosensor development. Ratajczak et al. (1998b) observed that while both medium- and long-chain n-alkanes $\left(\mathrm{C}_{7}-\mathrm{C}_{18}\right)$ induce alkM transcription in Acinetobacter sp. ADP1, the organism can only grow on larger alkanes $\left(>C_{12}\right)$, and this induction pattern was confirmed in an ADP1 AlkRbased biosensor (Zhang et al., 2012a). Interestingly, the opposite pattern of inducers vs. growth substrates is seen in GPo1. Shingler (2010) refers to these situations as "regulatory bottlenecks" for catabolic performance, and this should be kept in mind when investigating new bacterial isolates for development of hydrocarbon biosensors, i.e., the range of compounds a strain can utilise may not match the inducer range of its regulatory proteins. These phenomena are not unique to $A l k B$ regulation; e.g., in Rhodococcus sp. BCP1, transcription of smoABCD is induced by methane despite $\mathrm{BCP} 1$ being unable to use methane as a carbon source (Cappelletti et al., 2015).

Comparison of the AlkS regulators in P. putida GPol and A. borkumensis AP1 emphasises the diversity in bacterial hydrocarbon-sensing systems. There is $32 \%$ sequence identity between these two AlkS proteins, both contain a helix-turn-helix DNA binding domain, and both recognise a binding site upstream of the promoter which contains a $20 \mathrm{bp}$ inverted repeat; this motif is common to LuxR family regulators (Santos et al., 2012). The AlkS protein from P. putida GPo1 can cross-activate expression of the alkB1 gene in A. borkumensis (van Beilen et al., 2004), suggesting that the helix-turn-helix site 


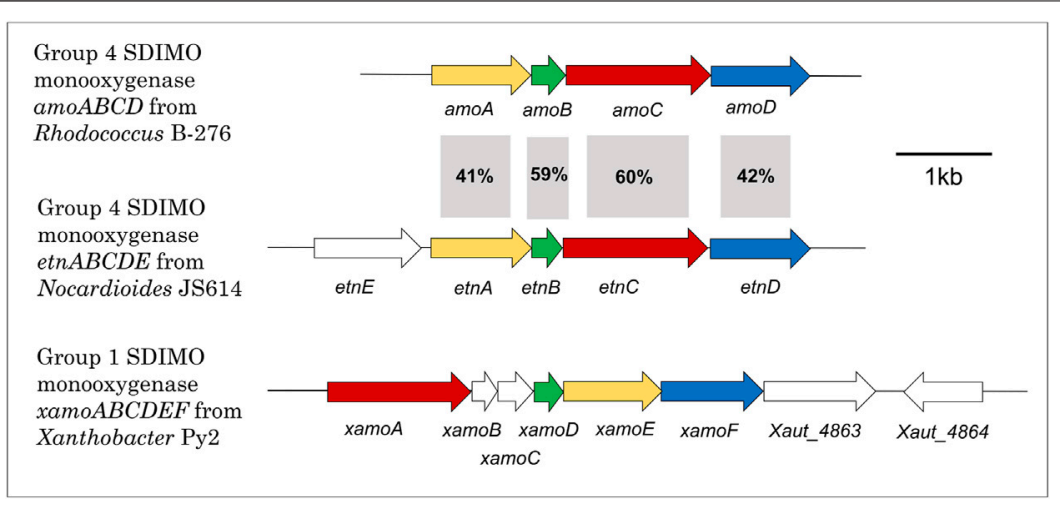

FIGURE 3 | Alkene monooxygenase gene cluster configurations in Xanthobacter Py2, Rhodococcus B-276 and Nocardioides JS614. Colours indicate type of gene in monooxygenase to aid with comparison between clusters. Yellow = beta subunit; green = coupling protein; red = alpha subunit; blue = rubredoxin; white fill = all other genes. \% identity also presented.

in the proteins and the cognate operator element in both species are functionally comparable. Despite these similarities, there are also many differences in the function of these two AlkS regulators, such as the constitutive vs. positive feedback mode of control of the regulator gene (see above section), and the presence in $P$. putida GPol of an additional inhibitory global regulation network via Hfq and Crc (Moreno and Rojo, 2017). Understanding the expression patterns of the regulatory proteins themselves is a key part of characterising the regulatory system as a whole.

\subsection{Limitations of Sequence Analysis}

Bioinformatic analysis of open reading frames in proximity to monooxygenase genes can be used to identify putative regulatory genes. For example, a gene upstream of the alkB2 monooxygenase in A. borkumensis SK2 encodes a GntR homolog, so a logical hypothesis might be that this GntR homolog is the regulator of the monooxygenase. More weight is added to this hypothesis when further analysis reveals that $A$. hongdengensis A-11-3, P. aeruginosa $R R 1$, and $P$. aeruginosa SJTD-1 also contain GntR-like proteins in the same position relative to their alkB2 genes (Wang and Shao, 2012; Liu et al., 2014). However, further work in strain SJTD-1 surprisingly revealed that CrgA, a LysR-type regulatory protein, was actually the regulator of the alkB2 gene, despite the fact that this regulator is $>300 \mathrm{~kb}$ away from the monooxygenase gene in the genome (Ji et al., 2019). This result was validated using knock-out, EMSA, footprinting, and promoter-probe assays, but it is not involved in the monooxygenase regulation.

\subsection{Added Complexity: Further Layers of Regulation of Monooxygenase Expression}

The transcription factors that respond to alkanes or their metabolites are not the only players in the regulation of alkane oxidation genes. Aside from methanotrophs and a few other obligate hydrocarbonoclastic bacteria, most hydrocarbonassimilating species isolated to date are heterotrophic generalists, and do not preferentially utilise n-alkanes. Therefore, confirming the absence of other more easily-utilised carbon sources is just as important for these bacteria as sensing the presence of the hydrocarbon. This is managed by catabolite repression (Moreno and Rojo, 2019). There is evidence that chemotaxis towards alkanes and alkane uptake are also strongly linked to the initial sensing and subsequent metabolism of alkanes in $A$. dieselolei, further reflecting that the expression of regulatory proteins for hydrocarbon detection can be influenced by, and linked to, other cellular functions (Moreno and Rojo, 2019).

Catabolite repression has been well-studied in P. putida GPo1, where the alkane degradation pathways are repressed by succinate, lactate, pyruvate or rich complex media like LB (Yuste et al., 1998; Dinamarca et al., 2003). Similarly, the prmA and smoA monooxygenases of Rhodococcus sp. BCP1 are repressed by succinate, glucose or LB medium in the presence of alkanes (Cappelletti et al., 2015), although AlkB from the same strain is not affected in the same way (Cappelletti et al., 2011). In B. cepacia RR10, glucose, arabinose, lactose and fructose repress alkB expression in the presence of the inducer tetradecanol (Marín et al., 2001). Interestingly, catabolite repression is not seen when alkB from $P$. putida GPo1 is heterologously expressed in E. coli, implying differences in these mechanisms between species (Staijen et al., 1999). This aligns with the fact that the preferred carbon sources of the two differ-glucose for $E$. coli, organic acids for Pseudomonas. It is likely that similar global catabolite repression systems exist in other facultative hydrocarbon oxidisers that are less well-characterised.

Product repression is another layer of control of expression of monooxygenases, and this can be exerted either directly or indirectly. In the case of the butane monooxygenase of $T$. butanivorans, fatty acids generated by the butane degradation pathway (typically butyrate) directly bind to and repress the monooxygenase (Doughty et al., 2006). Fatty acids also repress CYP153 in Dietzia sp. DQ12-45-1b (Liang et al., 2016a) and alkB in B. cepacia RR10 (Marín et al., 2001). The ability of fatty acids to repress alkane oxidation pathways has most likely evolved to 
prevent potential toxicity from the accumulation of such products (Moreno and Rojo, 2019).

Growth phase can also impact the regulation of monooxygenase-mediated pathways. Expression of the alkB monooxygenase in P. putida Gpo1 was significantly decreased when cells entered stationary phase compared to exponential phase (Yuste et al., 1998). This trend is also seen in $A$. borkumensis strains AP1 and SK2, where expression of alkB1 and alkB2 decreased in stationary phase (Schneiker et al., 2006). The opposite is seen with alkB expression in B. cepacia RR10 where detectable transcripts were highest at early stationary phase (Marín et al., 2001). Meanwhile, in P. aeruginosa PAO1, alkB1 is strongly expressed in late exponential phase while alkB2 is expressed more in early exponential phase (Marín et al., 2003). The molecular mechanisms behind these growth-phase dependent differences in regulation in these different species are unclear.

\section{REGULATORY SYSTEMS FOR ALKENE MONOOXYGENASES}

The enantioselectivity of epoxidation by alkene monooxygenases makes them valuable in the production of pharmaceutical precursors and other fine chemicals (Owens et al., 2009; Cheung et al., 2013). For this reason, research thus far has focused on the monooxygenase itself, leaving large gaps in our understanding of the regulation of these systems. An important distinction between the alkene and alkane monooxygenases is the fact that while alkane monooxygenases show activity on both alkanes and alkenes, and their regulatory proteins often accept both kinds of substrates if the carbon chain length is in the right range, the reverse is not true, and alkanes are generally not good substrates or inducers for alkene monooxygenases (Zhou et al., 1999). Because far fewer alkene-oxidising systems have been studied, the sections below are organised differently to the corresponding material on alkane regulation above, and we have taken a case-by-case approach, rather than attempting to draw general conclusions across all the systems.

Figure 3 shows the gene configuration of the two cases discussed below-Xanthobacter autrophicus Py2 (XamoABCDEF/Xamo) and Nocardioides sp. JS614 (EtnABCD/EtnMO). The shared subunits in these monooxygenases are $23-28 \%$ identical to each other, and it is clear the gene arrangement between the two is quite different. The sequence identity of each subunit is also compared to the amoABCD cluster from Rhodococcus rhodochrous B276, an archetypal alkene monooxygenase, for reference. As shown in the figure, the sequence identities between the B276 and JS614 subunits are much higher, between 41 and $60 \%$. This emphasizes the similarities in both organization and sequence in Actinobacterial clusters. The sequence identities between B276 and Py2 subunits were only 23-32\%. The regulation of the $R$. rhodochrous monooxygenase has not been characterized and so won't be examined in detail in this review.

\subsection{Regulation of Alkene Monooxygenase in Xanthobacter autotrophicus Py2}

The alkene monooxygenase of Xanthobacter Py2 (XamoABCDEF/Xamo) is a 6-component enzyme that belongs to SDIMO group 1 (Figure 3; Table 1). Strain Py2 was isolated on propene and Xamo was originally identified as a propeneoxidising enzyme (Ensign, 1996), but it also attacks aromatic compounds, and these can support the growth of Py2 (Zhou et al., 1999). One challenge in understanding how Xamo is regulated is uncertainty surrounding the nature of the inducer-it could be the alkene or an epoxide metabolite (Ensign, 1996); resolving this issue is tricky since the wild-type host will rapidly convert alkenes to epoxides, and to date, no effective heterologous expression systems have been reported either for the monooxygenase or the regulators. Early work on this system by Ensign (1996) showed that Xamo induction was possible even in cells grown on glucose, although Small and Ensign later reported that catabolite repression of Xamo occurred during growth on other carbon sources (Small and Ensign, 1997).

A promoter upstream of the XamoA subunit has been identified via sequence analysis, which is $60 \%$ identical to the sigma54-dependent promoter consensus sequence (Zhou et al., 1999). This is likely to be the promoter involved in the regulation of the monooxygenase expression.

Analysis of cosmid libraries provided evidence that the control of the Py2 propene monooxygenase might be part of a larger system. Complementation of mutants of Py2 with cosmid clones restored growth on epoxypropane, but interestingly, this activity became constitutive. This indicated that the $22 \mathrm{~kb}$ section of DNA in the cosmid contained the metabolic genes but not the necessary regulatory genes (Swaving et al., 1995), and further implied that the system was under at least one layer of negative regulation. The fact that the Py2 Xamo can also oxidise benzene, toluene and phenol suggests that this monooxygenase could be under long range control typical of aromatic hydrocarbon monooxygenases (Zhou et al., 1996).

A later shotgun proteomics study identified a candidate transcriptional regulator for the $\mathrm{Py} 2$ monooxygenase (Xaut_4864), that is encoded by a gene located between the Xamo gene cluster and the epoxide carboxylase gene cluster (Broberg and Clark, 2010). Xaut_4864 has a DNA binding domain similar to the MerR family of regulators but is missing 16 of 32 conserved residues typically found in MerR proteins, including the critical Cys82, and thus Xaut_4864 is thought to behave differently to MerR proteins in that it most likely does not need a metal ion to function. Xaut_4864 was identified as a protein expressed only in propylene-grown cells and thus is likely to be an activator of Xamo expression that also induces its own expression.

\subsection{Regulation of Alkene Monooxygenase in Nocardioides sp. JS614}

The alkene monooxygenase of Nocardioides JS614 (EtnABCD/ EtnMO) is quite different from that of Py2; this is a 4-component enzyme, part of SDIMO group 4 (Figure 3; Table 1), and enables 
TABLE 5 | Putative regulatory genes associated with monooxygenase clusters in Mycobacterium chubuense NBB4.

\begin{tabular}{|c|c|c|c|c|c|}
\hline Gene cluster & MO class & Substrates & $\begin{array}{l}\text { Putative regulatory } \\
\text { gene(s) }\end{array}$ & $\begin{array}{l}\text { Regulatory protein } \\
\text { family }\end{array}$ & References \\
\hline smoXYB1C1Z & SDIMO Group 3 & $\mathrm{C}_{2}-\mathrm{C}_{4}$ alkanes and alkenes & $\begin{array}{l}\text { MYCCH_RS28740 } \\
\text { MYCCH_RS28735 }\end{array}$ & $\begin{array}{l}\text { AcoR; CadC1 HTH domain } \\
\text { SigC-type transcription factor }\end{array}$ & Martin et al. (2014) \\
\hline pmoABCD & SDIMO Group 4 & Propene $^{a}$ & MYCCH_RS26755 & CdaR; GAF domain & Coleman et al. (2011a) \\
\hline hmoCAB & CuMMO & $\mathrm{C}_{2}-\mathrm{C}_{4}$ alkanes and alkenes & MYCCH_RS28775 & $\begin{array}{l}\text { AcoR; Fis HTH domain and PEP- } \\
\text { CTERM-box }\end{array}$ & Coleman et al. (2012) \\
\hline$s m o A B C D$ & SDIMO Group 6 & Propane $^{a}$ & $\begin{array}{l}\text { MYCCH_RS26425 } \\
\text { MYCCH_RS26430 }\end{array}$ & $\begin{array}{l}\text { LuxR; REC and HTH domains } \\
\text { Histidine kinase; GAF domain }\end{array}$ & Coleman et al. (2011a) \\
\hline etnABCD & SDIMO Group 4 & $\begin{array}{l}\mathrm{C}_{2}-\mathrm{C}_{8} \text { alkenes and } \\
\text { chlorinated alkenes }\end{array}$ & $\begin{array}{l}\text { EtnR1; } \\
\text { MYCCH_RS29055 } \\
\text { EtnR2; } \\
\text { MYCCH_RS29050 }\end{array}$ & $\begin{array}{l}\text { CdaR; PucR HTH domain } \\
\text { DmcR; MEDS domain }\end{array}$ & $\begin{array}{l}\text { Coleman et al. (2011a), Moratti } \\
\text { et al. (2016) }\end{array}$ \\
\hline $\begin{array}{l}\text { CYP153; fdx- } \\
\text { cyp-fdr } \\
\text { alkB-rubA1-rubA2 }\end{array}$ & $\begin{array}{l}\text { Cytochrome } \\
\text { P450 } \\
\text { alkB }\end{array}$ & $\begin{array}{l}\mathrm{C}_{5}-\mathrm{C}_{14} \text { alkanes }^{\mathrm{a}} \\
\mathrm{C}_{10}-\mathrm{C}_{16} \text { alkanes }^{\mathrm{a}}\end{array}$ & $\begin{array}{l}\text { MYCCH_RS28400 } \\
\text { MYCCH_RS28420 } \\
\text { MYCCH_RS06610 }\end{array}$ & $\begin{array}{l}\text { AraC } \\
\text { TetR } \\
\text { TetR }\end{array}$ & $\begin{array}{l}\text { Coleman et al. (2011a) } \\
\text { Coleman et al. (2011a) } \\
\text { Coleman et al. (2011a) }\end{array}$ \\
\hline
\end{tabular}

${ }^{a}$ These substrates predicted based on studies of homologous monooxygenases.

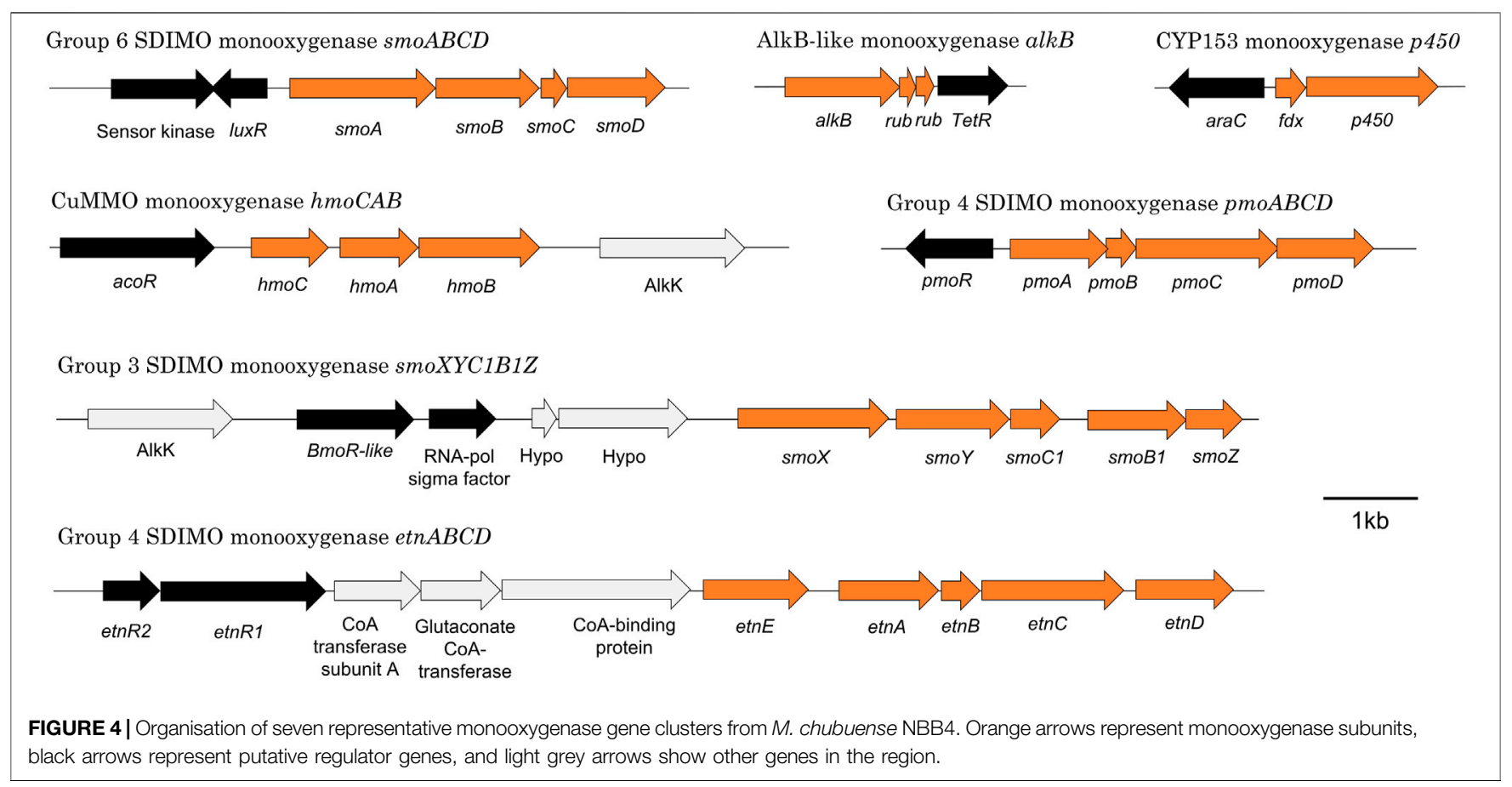

growth of the host on ethene and vinyl chloride. Despite being the first ethene-oxidising bacterium to be fully genome-sequenced (Coleman et al., 2011b), the regulatory mechanisms surrounding alkene degradation in Nocardioides sp. JS614 are still unclear. Early work on this organism revealed an unusual starvation response (Mattes et al., 2005; Chuang and Mattes, 2007), in which alkene-starved cultures or cultures pre-grown on acetate exhibited long lag periods before growth on alkenes recommenced. A key finding was that addition of ethene oxide (epoxyethane) eliminated the lag periods, suggesting that the epoxide was the inducer, and that the starvation response was due to the bacteria being initially unable to generate this inducer from the alkene substrate.

Peptide mass fingerprinting identified seven proteins in JS614 cells expressed in the presence of vinyl chloride, epoxyethane and ethene (Chuang and Mattes, 2007); these were all identified as components of the monooxygenase or putative downstream metabolic enzymes (e.g., dehydrogenases and transferases) but no regulatory proteins were detected. Inspection of the genome sequence of JS614 reveals that a two-component sensing system is encoded immediately adjacent to the alkene catabolic genes (see Figure 3 in Mattes et al., 2010); this consists of a CdaR family 
transcription activator and a DmcR family sensor kinase. Homologs of these regulators are also found adjacent to the alkene metabolic genes in other ethene-oxidising bacteria, but there is only preliminary experimental evidence to date to confirm their functions (see below Section 7).

Another clue about regulation of alkene oxidation in JS614 comes from Taylor et al. (2010), who found that the addition of ethene oxide to cultures allowed expansion of the growth substrate range to include propene and butene, which are normally cometabolised, but cannot support growth. These findings reinforce the hypothesis developed from earlier work that the epoxide is the inducer of the monooxygenase in JS614, and also highlight again the important distinction between inducers of regulatory proteins and substrates of catabolic enzymes. Understanding this distinction is critical to the successful development of biosensors and emphasises the importance of characterisation of regulatory proteins themselves, rather than trying to ascertain inducers based solely on the substrates of the monooxygenase.

\section{MYCOLICIBACTERIUM CHUBUENSE NBB4: A CASE STUDY OF DIVERSE ALKANE AND ALKENE MONOOXYGENASES AND REGULATORS}

Mycolicibacterium chubuense NBB4 (Coleman et al., 2006) is a hydrocarbon degrader originally isolated on ethene that can grow on many alkanes and alkenes, and is capable of co-metabolism of vinyl chloride and 1,2-dichloroethane (Coleman et al., 2011a). These activities are attributable to the diverse monooxygenases in NBB4 cells, including SDIMOs, AlkB, p450, and CuMMO (Table 5). Coordination of the activities of all these monooxygenases must involve complex regulation, which is thus far not understood. However, the availability of a genome sequence has allowed identification of the likely regulatory genes associated with each monooxygenase gene cluster (Figure 4; Table 5), and generation of hypotheses about their functions, as described below.

\subsection{Alkane Monooxygenase Regulation: smoXYB1C1Z, hmoCAB, smoABCD}

The alkane monooxygenases in $M$. chubuense NBB4 are a curious and diverse group. The smoXYB1C1Z gene cluster encodes a group 3 SDIMO that is active on $\mathrm{C} 2-\mathrm{C} 4$ alkanes and alkenes (Martin et al., 2014). There are two putative regulator genes near the smo genes; one of these is predicted to encode an AcoR-like regulatory protein that is distantly related to the regulators of other group 3 SDIMOs (BmoR and MmoR; 10\% amino acid identity) (Coleman et al., 2011a) and has 30\% identity to the closest characterised protein (acetoin dehydrogenase activator AcoR from B.subtilis 168 (Ali et al., 2001). The other regulator near the smo genes encodes a SigC-like sigma factor; there is no parallel for this in the other group 3 SDIMOs. There is thus far no experimental evidence to confirm that either of these regulatory proteins control smoXYB1C1Z expression, but their positioning relative to the smo genes indicates that this is likely.

The $h m o C A B$ genes encoding a CuMMO are located immediately upstream of the smoXYB1C1Z genes in the NBB4 genome (Coleman et al., 2012). This organisation and the common substrates shared by both these monooxygenases (gaseous alkanes and alkenes) suggests that they may be coregulated. Previous hypotheses about the relationship between the Smo and Hmo enzymes include the possibility that they might be a high- and low-affinity pair or that they are expressed in environments with different cofactor metal availabilities (Martin et al., 2014). The $h m o C A B$ cluster is preceded by another acoRlike regulator gene, which suggests that the two clusters may have their own independent regulatory systems. It is possible that there are multiple layers of regulation over these two monooxygenases; this would be consistent with a hypothesis that their expression is controlled by both substrate and cofactor availability.

The smoABCD cluster of NBB4 encodes a group 6 SDIMO which is thus far uncharacterised except for bioinformatics (Coleman et al., 2011a). The smoABCD genes are adjacent to a gene encoding a LuxR-type regulator (van Kessel et al., 2013), which is oriented "head-to-head" with a gene encoding a sensor kinase, with a 29 bp overlap between the $3^{\prime}$ ends of the two genes. It is common for LuxR regulators to belong to two-component transduction systems with a sensor kinase, so it is plausible that this pair of proteins act together in this way. The closest homolog of this NBB4 regulator with a known function is the cold-shock regulator DesR in B.subtilis 168, at $26 \%$ amino acid identity (Cybulski et al., 2004).

Analysis of the regulation of the smoABCD monooxygenase in Rhodococcus sp. BCP1 gives clues to the regulation of $s m o A B C D$ in NBB4; these two SDIMOs are very similar, sharing $85-94 \%$ amino acid identity in the enzyme subunits. In strain BCP1, the promoter region contains the same core inverted repeat, potential -35 site, and putative catabolite repressor protein binding sites as seen in NBB4 (Cappelletti et al., 2015), along with luxR and sensor kinase genes that are 90 and $86 \%$ identical, respectively. Based on RT-PCR experiments (Cappelletti et al., 2015) the BCP1 smo genes are known to be inducible by $\mathrm{C} 1-\mathrm{C} 7$ alkanes and repressible by glucose or complex media (LB), suggesting the NBB4 smo genes are also under similar controls.

\subsection{Alkane Monooxygenase Regulation: CYP153 and alkB}

The CYP153 gene cluster in NBB4 is flanked by genes encoding two regulator proteins-a TetR-like protein and an AraC-like protein (Table 5). The araC-like gene and the CYP cluster are divergently transcribed, with just $115 \mathrm{bp}$ separating them; this organisation is consistent with the AraC homolog being the regulator responsible for controlling CYP153 in NBB4, and with promoters of these two genes being located in this $115 \mathrm{bp}$ region. A TetR-like protein is encoded by a gene adjacent to the AlkB-like monooxygenase gene cluster in NBB4. This protein is $31 \mathrm{bp}$ downstream of the $a l k B$ and putative $r u b$ genes, and oriented in the same direction as both alkB and $r u b$ genes. 
There are many similarities in the configuration of CYP153 and alkB in NBB4 and in Dietzia sp. strain DQ12-45-1b. The alkB homolog in Dietzia (alkW1) is under the control of a TetR-family repressor; this kind of regulation of alkB appears to be unique to the Actinobacteria (Liang et al., 2016b). The regulator alkX is 19 bp downstream of the rubredoxin gene in Dietzia compared to $31 \mathrm{bp}$ in NBB4. The intergenic DNA region upstream of alkB in both species is $53 \%$ identical. The -35 and -10 sites of the alkW1 promoter each differ by just one base from the equivalent alkB promoter in NBB4, and the operator sequences in NBB4 have strong homology and similar spacing to those seen in Dietzia (Liang et al., 2016a). The configuration of the $\operatorname{araC}$ family gene in the CYP153 cluster of Dietzia is also very similar to the situation in NBB4, i.e., oriented divergently and separated from the ferredoxin gene by 118 bp (Liang et al., 2016b).

If the functional parallels between these monooxygenases in NBB4 and Dietzia reflect the sequence similarities, one could infer that the CYP153 and alkB genes in NBB4 work as part of a team to efficiently tackle alkanes across a wide range of chain lengths. Nie et al. described how the inducer and substrate range of CYP153 and alkB in Dietzia are complementary, i.e., CYP153 hydroxylates $n$-alkanes < C10, while AlkW1 acts on > C10 substrates (Nie et al., 2014b). It is worth noting that NBB4 has two further CYP153 genes (not discussed in detail here), which adds further complications to understanding the relationship between enzymes, inducers and substrates (Coleman et al., 2011a), and highlights the fact that much further work is needed to understand the regulation of alkB and CYP153 in NBB4 and similar bacteria.

\subsection{Alkene Monooxygenase Regulation: pmoABCD, etnABCD}

The substrate ranges of the NBB4 ethene and propene monooxygenases (EtnABCD and $\mathrm{PmoABCD}$, respectively) are similar; both enzymes show activity on $\mathrm{C}_{2}-\mathrm{C}_{8}$ alkenes, with stronger activity on gaseous alkenes $\left(\mathrm{C}_{2}-\mathrm{C}_{4}\right)$ ( $\mathrm{McCarl}$ et al., 2018). The fact that strain NBB4 possesses two distinct SDIMO enzyme systems with very close overlap in substrate ranges is unusual and poses questions about why this genotype has evolved and how these genes are regulated. This is an excellent example of why monooxygenase regulatory systems warrant further investigation.

The pmoABCD gene cluster in Mycolicibacterium NBB4 has a $\mathrm{CdaR}$ family regulator encoded by a gene immediately upstream of the monooxygenase, and divergently oriented from these. This family of regulators was originally studied for their role in sugar diacid regulation in $E$. coli, and are typically activators containing a helix-turn-helix domain at the C-terminus (Monterrubio et al., 2000). A similar gene organisation is seen for $p m o A B C D$ of Mycobacterium M156 (Coleman et al., 2011a), although neither regulatory system has been characterised beyond DNA sequencing and bioinformatic analysis.

Regulation of etnABCD is likely to be done by a pair of regulators EtnR1/EtnR2, encoded by genes upstream of etnABCD. The EtnR1/EtnR2 pair display the typical features of a bacterial two-component regulatory system in which a DNA- binding protein (transcriptional regulator) is phosphorylated by a histidine protein kinase (sensor protein). EtnR1 is a CdaR family protein that contains a DNA-binding helix-turn-helix domain. EtnR2 is distantly related to the DcmR dichloromethane-sensing regulator from Methylobacterium DM4 (16\% aa identity, 27\% aa similarity), and contains a MEDS domain, which is involved in sensing hydrocarbon derivatives in both methanogens and methylotrophs (Anantharaman and Aravind, 2005).

Preliminary research has confirmed an interaction between EtnR1 and a DNA segment containing etn $P$, its putative cognate promoter, via EMSA (Moratti et al., 2016). Transcriptomics data (unpublished) also shows a significant upregulation (approx. 8fold) of both etnR1 and etnR2 after exposure of NBB4 cells to ethene; this is consistent with these genes being positive regulators that activate their own expression in a feedback loop, similar to the situation discussed above with AlkS in $P$. putida GPo1. Importantly, the transcriptomics data from NBB4 shows no reads from the short intergenic region thought to contain the etnP promoter sequence, consistent with this region driving expression but not itself being expressed.

The $e t n R 1$ and $e t n R 2$ regulators are highly conserved (73-78\% aa identity) across many ethene-oxidising isolates, including Mycolicibacterium JS623 (etnR1: WP_015305844, etnR2: WP_015305843), Mycolicibacterium tusciae JS617 (etnR1: WP_006247394, etnR2: WP_006247393), and Mycolicibacterium rhodesiae JS60 (etnR1: WP_014211282, etnR2: WP_014211281). More divergent homologs of these genes (44-59\% aa identity) can also be found in many other Actinobacteria, including but not limited to Streptomyces thermoautotrophicus H1 (etnR1: WP_066887198, etnR2: WP_079045917) and Amycolatopsis SYSUP0005 (etnR1: WP_101434350, etnR2: WP_158242445). Nearly all these bacteria also contain etn $A B C D$ homologs near the regulator genes, although most have not been tested for alkene oxidation. Unlike the regulation of alkB described above, this suggests that there is overall consistency in the regulation of alkene oxidation across all gram-positive bacteria.

\section{CONSTRUCTING A HYDROCARBON BIOSENSOR: GENERAL CONSIDERATIONS}

There are two general approaches for constructing whole-cell transcription-factor based biosensors. The first approach involves the assembly and expression of the regulatory gene(s), promoters and reporter gene in a plasmid in an appropriate heterologous host strain; this approach allows for more control over expression of the different elements because promoters, ribosome binding sites and other features can be easily and individually modified. The second approach involves the integration of the reporter gene into the genome of the native host, either immediately upstream of the metabolic genes or replacing these; in this situation, there is a gain in stability of the system but the trade-off is that there is less flexibility and construction is more difficult. There are advantages and disadvantages of both approaches, depending on the intended applications of the system (Carpenteret al., 2018). 
TABLE 6 | Compilation of existing hydrocarbon biosensors.

\begin{tabular}{|c|c|c|c|c|c|c|c|}
\hline $\begin{array}{l}\text { Sensing } \\
\text { components }\end{array}$ & Reporter & Host & Type & $\begin{array}{c}\text { Inducers } \\
\text { and detection limits }\end{array}$ & $\begin{array}{c}\text { Best } \\
\text { inducer }\end{array}$ & Intended application & References \\
\hline \multirow[t]{5}{*}{$\begin{array}{l}\text { alkS/P } P_{\text {alkB }} \text { from } P . \\
\text { putida GPo1 }\end{array}$} & $14 \times A B$ & E. coli $\mathrm{DH} 5 a$ & Plasmid & $\begin{array}{l}\mathrm{C}_{6}-\mathrm{C}_{10} \text { linear alkanes, } \\
4-100 \mathrm{nM}\end{array}$ & $\mathrm{C}_{8}$ alkane & Monitoring bioremediation & Sticher et al. (1997) \\
\hline & $g f p$ & E. coli $\mathrm{DH} 5 a$ & Plasmid & $\begin{array}{l}\mathrm{C}_{8} \text { alkane, } 10 \mathrm{nM} \\
\text { to } 1 \mu \mathrm{M}\end{array}$ & $\mathrm{C}_{8}$ alkane & Monitoring bioremediation & Jaspers et al. (2001) \\
\hline & $g f p$ & A. borkumensis & Plasmid & $\mathrm{C}_{8}$ alkane, petrol & N/A & Monitoring bioremediation & Sevilla et al. (2015) \\
\hline & $g f p$ & E. coli $\mathrm{DH} 10 \beta$ & Plasmid & $\mathrm{C}_{5}-\mathrm{C}_{12}$ alkanes & $N / A$ & Monitoring bioremediation & Reed (2012) \\
\hline & $s f-g f p$ & $\begin{array}{l}\text { E. coli } \mathrm{DH} 5 \mathrm{aZ} 1 \\
\text { and } E \text {. coli HB101 }\end{array}$ & Plasmid & $\mathrm{C}_{8}, \mathrm{C}_{10}, \mathrm{C}_{11}$ alkanes & $\mathrm{N} / \mathrm{A}$ & $\begin{array}{l}\text { Intracellular alkane detection; } \\
\text { characterisation of AlkL }\end{array}$ & Grant et al. (2014) \\
\hline $\begin{array}{l}\text { alkJ/alkBFG from } P \text {. } \\
\text { putida GPo1 }\end{array}$ & $\operatorname{lu} \times A B$ & E. coli TOP10 & Plasmid & $\begin{array}{l}\mathrm{C}_{5}-\mathrm{C}_{12} \text { alkanes, } \\
\text { alcohols, aldehydes } \\
10-200 \mu \mathrm{M}\end{array}$ & $\mathrm{C}_{8}$ alkane & $\begin{array}{l}\text { Intracellular alcohol and } \\
\text { aldehyde detection in } \\
\text { metabolic engineering }\end{array}$ & $\begin{array}{l}\text { Minak-Bernero et al. } \\
(2004)\end{array}$ \\
\hline $\begin{array}{l}\text { alkS } S_{A B} / P_{\text {alkB1 }} \text { from } \\
\text { A. borkumensis }\end{array}$ & $\begin{array}{l}\text { luxAB } \\
\text { or } g f p\end{array}$ & E. coli DH5a & Plasmid & $\begin{array}{l}\mathrm{C}_{14} \text { alkanes, crude } \\
\text { oil, } 5 \mathrm{nM}\end{array}$ & $\mathrm{C}_{8}$ alkane & Monitoring bioremediation & Kumari et al. (2011) \\
\hline \multirow[t]{3}{*}{$\begin{array}{l}\text { alkR/P } \mathrm{P}_{\text {alkM }} \text { from } A . \\
\text { baylyi ADP1 }\end{array}$} & $\operatorname{lu} \times A B$ & $\begin{array}{l}\text { A. baylyi } \\
\text { ADPWH_alk }\end{array}$ & Chromosomal & $\begin{array}{l}\mathrm{C}_{7}-\mathrm{C}_{36}, \text { alkanes and } \\
\text { alkenes, } 100 \mu \mathrm{M}\end{array}$ & $\mathrm{C}_{8}$ alkane & Monitoring bioremediation & $\begin{array}{l}\text { Zhang et al. (2011), } \\
\text { Zhang et al. (2012a), Li } \\
\text { et al. (2013) }\end{array}$ \\
\hline & $\begin{array}{l}l u \times A B \\
\text { and } g f p\end{array}$ & A. baylyi ADP1 & Chromosomal & $\begin{array}{l}\mathrm{C}_{12}-\mathrm{C}_{18} \text { alkanes and } \\
\text { aldehydes }\end{array}$ & $\begin{array}{l}\mathrm{C}_{12} \\
\text { alkane }\end{array}$ & $\begin{array}{l}\text { Intracellular alkane detection } \\
\text { in metabolic engineering }\end{array}$ & $\begin{array}{l}\text { Santala et al. (2012), } \\
\text { Lehtinen et al. (2017) }\end{array}$ \\
\hline & $g f p$ & $\begin{array}{l}\text { E. coli BL21 DE3 } \\
\Delta \text { fadE }\end{array}$ & Plasmid & $\mathrm{C}_{15}, \mathrm{C}_{17}$ alkanes & $\mathrm{N} / \mathrm{A}$ & $\begin{array}{l}\text { Intracellular alkane detection } \\
\text { in metabolic engineering }\end{array}$ & Wu et al. (2015) \\
\hline $\begin{array}{l}\text { bmoR/P } \text { BMo from } T \text {. } \\
\text { butanivorans } \\
\text { sp. nov }\end{array}$ & $\begin{array}{l}\text { tetA-gfp } \\
\text { fusion }\end{array}$ & E. coli DH1 $\Delta$ adhE & Plasmid & $\begin{array}{l}\mathrm{C}_{3} \mathrm{C}_{4} \text { alcohols, } \\
0.01-100 \mathrm{mM} \\
\mathrm{C}_{4} \text { aldehyde } \\
1.0-7.5 \mathrm{mM}\end{array}$ & $\begin{array}{l}\mathrm{C}_{4} \\
\text { alcohol }\end{array}$ & $\begin{array}{l}\text { Intracellular alcohol detection } \\
\text { in metabolic engineering }\end{array}$ & Dietrich et al. (2012) \\
\hline
\end{tabular}

For environmental applications e.g. in monitoring bioremediation, precise detection at a single cell level is not necessary, and detecting average hydrocarbon concentrations in a population of biosensor cells is acceptable; note that given current legal and biosafety considerations it is more likely that these analyses would be done in vitro rather than in situ. In a metabolic engineering context, detection at a single-cell level may be desirable e.g. for screening clones in a directed evolution library (Dietrich et al., 2012), and in such applications, a resistance gene may be used instead of a reporter gene to select for the target phenotype (Dietrich, 2011; Carpenter et al., 2018). Challenges to using biosensors at a single-cell level include variations in expression level in individual cells, the potential impact on cell viability, and the impact of the surrounding population on single cells (Tecon and van der Meer, 2006; Carpenter et al., 2018).

The type of replication origin and the host species are key considerations for plasmid-based biosensor construction. Different origins of replication will give different copy numbers, which will impact the signal strength produced by the biosensor (Carpenter et al., 2018). Plasmid-based systems enable the use of hosts that are non-pathogenic, fast to grow and easy to transform, but possible disadvantages include a lack of robustness outside the laboratory, problems with the inducible promoter not being recognised correctly, and potential codon usage issues (Carpenter et al., 2018). Codon optimisation or harmonisation methods can be applied to the regulatory protein and/or to the reporter gene to overcome codon usage problems.
Chromosomally-integrated biosensors will be single-copy systems, and the output signal strength thus correspondingly lower than for plasmid-based systems. Chromosomallyintegrated biosensors in non-standard hosts can be more useful for environmental applications, or under harsher physicochemical regimes where traditional host strains would not survive (Jiang et al., 2020). Chromosomal biosensors do not require any selection pressure to maintain, which offers a practical advantage in environmental applications (de las Heras and de Lorenzo, 2010). A major disadvantage of chromosomally-integrated biosensors is the difficulty of construction, since nonstandard microbial species have more limited genetic tools and methods available. Homologous recombination has typically been used to make the precise insertions required, but more modern methods such as CRISPR will increasingly replace this (Arroyo-Olarte et al., 2021).

Several problems with chromosomal biosensors relate to interference of different kinds; this may arise from other inducers, other enzyme systems, other global regulators, or other cells in the environment ( $\mathrm{Su}$ et al., 2011; Jiang et al., 2020). Wild-type microbes that have been engineered to contain a hydrocarbon biosensor circuit may might have other enzyme systems that can metabolise the inducer; this will lead to a depressed response or false negative signals. Less well-studied hosts may contain global control networks that interact with the promoter of interest in unknown ways. For environmental applications or mixed culture conditions, major unknown factors arise from the possible interactions between the 
biosensor and other microbes; these may create or consume inducers, or enhance/inhibit growth or metabolism in other ways.

\section{EXISTING ALIPHATIC ALKANE BIOSENSOR PROTOTYPES}

There have been eleven unique hydrocarbon biosensors developed to date (Table 6) using components from four alkane-degrading bacteria ( $P$. putida, A. borkumensis, A. baylyi, and T. butanivorans). These have been designed either for monitoring the bioremediation of oil spills (detection of extracellular alkanes) or to increase our understanding of hydrocarbon metabolism and/or engineer strains for hydrocarbon synthesis (detection of intracellular alkanes, alcohols or aldehydes). The $b m o R / \mathrm{P}_{\mathrm{BMO}}$ biosensor derived from $T$. butanivoras is notable in this collection because it is the only example to date of a SDIMO-associated regulator employed as a biosensor (Dietrich et al., 2012), and because it provides an important reminder that these systems are in some cases induced by metabolites (in this case 1-butanol) rather than alkanes; this is not necessarily a disadvantage, and reflects the broader potential of monooxygenase regulatory systems in biotechnology.

\subsection{Plasmid-Based Alkane Biosensors}

More plasmid-based alkane biosensors have been developed than chromosomally-integrated ones, and the majority of these are based on $\mathrm{AlkS} / \mathrm{P}_{\text {alkB }}$ from P.putida GPol (Table 6). The output signals from these include GFP or LuxAB (detection), or TetA (selection) (Dietrich et al., 2012). Some have the input and output components on separate plasmids (Sticher et al., 1997; Reed et al., 2012), while others use single-plasmid systems (Jaspers et al., 2001; Minak-Bernero et al., 2004; Kumari et al., 2011; Sevilla et al., 2015) (See Figure 1 of Reed et al. (2012) and Figure 1 of Jaspers et al. (2001) for representative plasmid-based biosensor schematics). One novel biosensor uses the monooxygenase genes alkJ/alkBFG to convert alkanes to aldehydes, which then support luciferase activity (Minak-Bernero et al., 2004). Another example of note uses AlkR/P $\mathrm{P}_{\text {alkM }}$ from A. baylyi ADP1 to measure pentadecane and heptadecane biosynthesis from the ado and aar genes of Synechococcus integrated into an E. coli host, via a GFP output (Wu et al., 2015). Most plasmid-based biosensors are maintained in lab strains of E. coli such as DH5a (Sticher et al., 1997; Jaspers et al., 2001; Kumari et al., 2011), DH10ß (Reed et al., 2012) or TOP10 (Minak-Bernero et al., 2004). An exception is one system using A. borkumensis as a host; this had a slower response time, but higher sensitivity (Sevilla et al., 2015).

\subsection{Chromosomal Biosensors}

Only two chromosomally-integrated alkane biosensors have been developed to date, both in A. baylyi ADP. The first of these (named ADPWH_alk) has luxCDABE integrated upstream of alkM1, controlled by AlkR/PalkM1 (Zhang et al., 2012b), and has been used for biosensing in an oil-contaminated sample (Li et al., 2013) and further engineered for increased functionality by immobilisation on magnetic nanoparticles (Zhang et al., 2011) (see Figure 1A in Zhang et al., 2012a) for a representative chromosomal biosensor schematic). The other chromosomallyintegrated biosensor allows simultaneous detection of intracellular alkanes and aldehydes. In this sensor, a cassette

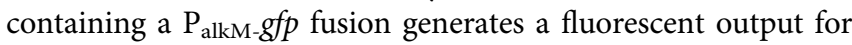
alkane detection while a $\operatorname{lu} x A B$ cassette reports on aldehyde concentrations (long-chain aldehydes are the substrate for the luciferase). The system allows reporting on both alkane oxidation to aldehydes and alkane synthesis from aldehydes, since it also contains IPTG-inducible alkane biosynthesis genes (aar and ado) (Lehtinen et al., 2017).

\subsection{Benefits and Limitations}

The low bioavailability of hydrocarbons is a major challenge for alkane biosensors, which all under-report hydrocarbon concentration by around 20\% (Sticher et al., 1997; Kumari et al., 2011; Zhang et al., 2012a; Li et al., 2013). Kumari et al. (2011) found that a longer incubation time was required to increase the bioavailability, and hence detection, of longer chain alkanes $\left(>C_{11}\right)$, while Sticher et al. (1997) attributed the underestimation to the presence of unknown inhibitor compounds. Li et al. (2013) argued that, despite these shortcomings, the benefits of biosensors still made them valuable, and in the case of their system, the short detection time (0.5-4 vs. $48 \mathrm{~h}$ for GC/MS) and the small sample size $(1 \mathrm{ml}$ vs. $500 \mathrm{ml}$ required for $\mathrm{GC} / \mathrm{MS}$ ) were major advantages. Biosensors can be surprisingly robust; e.g., Zhang et al. did not observe any instability or loss of function in their ADPWH_alk biosensor, which still worked well after storage for a month in water at $4^{\circ} \mathrm{C}$ (Zhang et al., 2012a).

\section{DEVELOPMENT AND OPTIMISATION OF HYDROCARBON BIOSENSORS}

An increased understanding of regulatory components opens the door to protein and DNA engineering to optimise the specificity, sensitivity, dynamic range, detection range and response time of these systems for use as biosensors (Ding et al., 2021). The flexibility of regulatory proteins in detecting multiple inducers can be seen as a double-edged sword (Diplock et al., 2010); this may be useful in nature for a bacterium to respond to multiple possible carbon sources, but may not be ideal for biosensing of specific analytes. Factors targeted for optimisation include host strain, promoter sequence, replication origin, ribosome binding site, protein-promoter binding sites, and the sequence of the regulatory protein; the latter may also involve addition of degradation tags to reduce the metabolic burden on the cell (Ding et al., 2021).

Techniques such as site-directed mutagenesis, random PCR mutagenesis and DNA shuffling can be used to generate libraries of regulator variants with improved functions (van der Meer and Belkin, 2010). Regulatory proteins of the AraC/XylS and TetR families have successfully been mutated to alter binding specificity (Galvão et al., 2006); e.g., the R41G mutation in XylS increases the response to 2-ethylbenzoate, while reducing the response to 2-methylbenzoate (Galvão et al., 2006). The 


\section{A Octane biosensor}

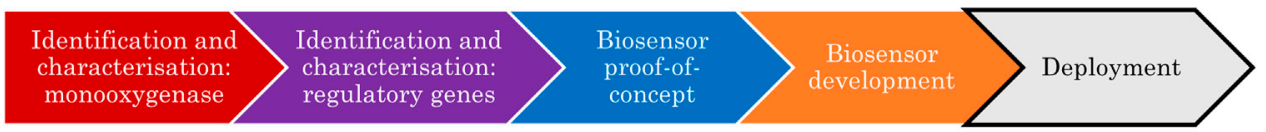

B Medium-chain alkane biosensors

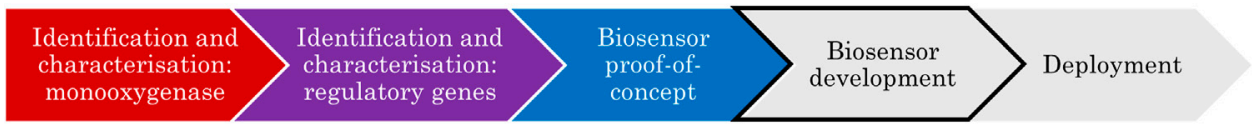

C Alkene biosensors

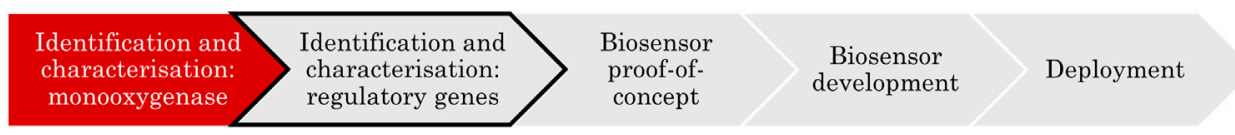

FIGURE 5 | Status of development of octane (A), medium-chain alkane (B), and alkene biosensors (C), with priority research areas yielding maximum impacts indicated by the dark outlined arrows.

crystal structure of a protein can reveal optimal sites for mutation; this approach was successfully used in the case of DntR, a salicylate-induced activator in $P$. putida, to identify the binding pocket (Lönneborg et al., 2007).

An impressive example of optimisation involved the directed evolution of $A l k S$ in an $E$. coli-based $A l k S / P_{a l k B}$ biosensor (Reed et al., 2012). Two rounds of error-prone PCR resulted in the identification of several mutations that conferred improved response to short-chain alkanes $\left(\mathrm{C}_{5}-\mathrm{C}_{9}\right)$, with the best mutant showing a five-fold increase in fluorescence output in response to hexane compared to wild type AlkS. The Q410K and S470T mutations were present in the two best mutants; the latter increases the bulkiness in the putative alkane binding pocket, discouraging binding of larger alkanes (Reed et al., 2012). This study provides clear evidence for the usefulness of directed evolution approaches to alter the substrate range and specificity of alkane-sensing systems.

A novel approach to biosensor development was taken by Zhang et al. (2011), who functionalised the A.baylyi ADPWH_alk biosensor using magnetic nanoparticles, to allow for remote manipulation of the reporter cells; this allows biosensor cells to be collected for re-use after deployment in a complex environment by application of a magnetic field. The magnetic nanoparticles had no adverse impact on cellular function or alkane detection and could be attached with an efficiency of 99.96\%. The ADPWH_alk biosensor has a shorter response time (30 $\mathrm{min}$ ) compared to a previously-developed biosensor using the same AlkR/P $P_{\text {alkM }}$ components (10 h) (Ratajczak et al., 1998a); this is potentially attributable to three fortuitous point mutations located near the AlkR binding site (Zhang et al., 2012b).

The 1-butanol biosensor constructed using BmoR/ $\mathrm{P}_{\mathrm{BMO}}$ and GFP has also been optimised (Dietrich, 2011). In this case, lower temperature $\left(25^{\circ} \mathrm{C}\right)$ and lower levels of $\mathrm{BmoR}$ expression resulted in a more robust biosensor. A synthetic ribosome binding site for $g f p$ expression was also beneficial, resulting in higher fold- induction and better dynamic range. Other parameters that were optimised included: induction time (early exponential phase was best), inducer concentration (alcohol toxicity was observed above $40 \mathrm{mM}$ 1-butanol), host strain ( $\triangle a d h E$ strain lowered background fluorescence) and plasmid origin of replication (a low copy replicon gave no fluorescence).

Calibration of biosensors to traditional detection techniques is a crucial step towards real-world application, as it proves the integrity and reliability of the device. This was done with the $A$. baylyi ADPWH_alk biosensor, by comparing it to GC/MS measurements (Li et al., 2013). Two contaminated soil samples ( $>5,000 \mathrm{mg}$ petroleum $/ \mathrm{kg}$ soil) were analysed along with two clean soil samples from an adjacent site. It was found that the biosensor reported $\sim 20 \%$ lower levels of oil compared to the GC/ MS, which could be attributed to the low bioavailability of alkanes, as discussed above (Sticher et al., 1997). Inducer bioavailability has been a consistent problem for biosensor development, but a counter-argument can also be made that the bioavailable fraction is more relevant than the total hydrocarbons for determining ecotoxicity (Tecon and Van der Meer., 2008). Enhancing the uptake of alkanes may increase their apparent bioavailability; e.g., co-expression of the AlkL transporter in an E. coli strain expressing the AlkB monooxygenase resulted in a 100 -fold increase in oxidation of large alkanes $\left(>\mathrm{C}_{12}\right)$ (Grant et al., 2014).

A recent biosensor optimisation study examined the impact of different host organisms on the performance of the biosensor. A dual plasmid biosensor containing AlkS and $P_{\text {alkB }}$ with a GFP reporter was transformed into several alkane-assimilating marine bacteria, and also into E. coli (Sevilla et al., 2015). Although E. coli had the fastest detection rate, $A$. borkumensis was the best candidate overall, giving the most sensitive detection of octane (detection limit of $0.5 \mu \mathrm{M}$ ), and also effectively detecting $\mathrm{C}_{7}-\mathrm{C}_{9}$ alkanes at $0.012 \% \mathrm{v} / \mathrm{v}$ concentration in a saltwater sample. This is an excellent example of how a hydrocarbon biosensor can be 
optimised for a specific application-in this case, monitoring bioremediation of oil spills in oceans-by changing the host organism of the sensor.

\section{BRINGING HYDROCARBON BIOSENSORS TO MARKET}

Despite the above-described successes with optimisation, no hydrocarbon biosensors are commercially available at the time of writing. The deployment phase of a whole-cell microbial biosensor is challenging, particularly for devices that have environmental applications. The use of microbial biosensors in the environment and the associated challenges with their deployment have been extensively reviewed (D'Souza, 2001; van der Meer et al., 2004; Harms et al., 2006; de las Heras and de Lorenzo, 2010; Coleman et al., 2011a; de las Heras and de Lorenzo., 2012; Plotnikova et al., 2016; Shemer and Belkin, 2019; Hicks et al., 2020; Jiang et al., 2020); here we will focus on a few key engineering considerations relevant to the specific case of hydrocarbon biosensors. The potential of these systems has been long acknowledged, and yet the same barriers seem to stand in the way, decades after they were first recognized. These barriers include legal considerations surrounding the release of genetically manipulated bacteria, financial issues about the investment of time and resources required to yield sufficiently optimised systems for field application (Sadana and Sadana, 2011), and functional limitations of these biosensors, such as bioavailability concerns (van der Meer, 2016).

Two linked challenges for biosensor commercialisation are culture scale-up and immobilisation. Large numbers of cells need to be grown in pure culture and kept viable and at high activity; continuous culture is a good option here, but this requires more complex equipment and maintenance and has a higher risk of contamination (Bjerketorp et al., 2006). Cells then need to be preserved, immobilised and/or contained such that they can be deployed safely and effectively without compromising their functionality; these methods may include freeze- or vacuumdrying, immobilisation and/or encapsulation. Cells can be immobilised on solid surfaces like optical fibres or microchips, or encapsulated in soft materials like hydrogels, sol-gel, carrageenan, alginate, polyacrylamide, oxysilane or polyvinyl alcohol (Liu et al., 2007). The choice of encapsulation/ immobilisation methods impacts many aspects of biosensor function, such as the rates of gas and solute diffusion, biosensor response time, cell viability, and shelf-life.

Striking a balance between functionality and biosafety is an ongoing challenge for all whole cell-based biosensors that have intended applications outside of the laboratory. The inclusion of toxin/anti-toxin systems, non-canonical amino acids, kill switches, engineered auxotrophy, or conditional origins of replication are examples of methods to prevent unintentional gene transfer from the biosensor to the environment (Wright et al., 2015; Hicks et al., 2020). Given the high cost and labour inputs into their production, the potential to reuse or recycle these biosensors should also be considered (e.g., see abovedescribed example using magnetic nanoparticles (Zhang et al.,
2011). If the biosensor is intended for single use, biodegradation options should be assessed, e.g., by choosing a biodegradable immobilisation surface. Testing the function of a biosensor in its intended application environment is very important since other chemical compounds or microbes in the target sample could inhibit or confound its response (van der Meer and Belkin, 2010); elucidating these interactions should be an early focus of the deployment phase of biosensor development.

\section{FUTURE RESEARCH PRIORITIES AND CONCLUSIONS}

One useful analogy for the landscape of aliphatic hydrocarbon biosensor development is the research funnel. Identifying the bottlenecks in this funnel is the key to efficiently directing research for different kinds of biosensors. At the top of the funnel, there is an abundance of putative monooxygenase and other hydrocarbon catabolic genes in databases that have been tentatively identified using bioinformatics. There is then a steep decline at the next level, representing experimentally characterised catabolic systems, with only a few dozen monooxygenases reaching this milestone. The identification and characterisation of the regulatory systems at the next two lower levels filter the candidates even further. Only a handful of biosensors make it to proof-of-concept stage, with optimisation and development attempts made on an even smaller subset of these, and thus far no candidates have been deployed as commercial products.

The large number of putative monooxygenase genes already existing in databases reflects the constantly decreasing cost of DNA sequencing, and the availability and accessibility of bioinformatic software; this part of the funnel is not the best focus for efforts to develop biosensors. The characterisation of monooxygenases is also not a major limiting factor since many representatives of different monooxygenases have now been at least partially characterised. In contrast, there are strong arguments for focusing research efforts on identifying and characterising regulatory genes and promoters. Extrapolating from previous well-studied systems is of limited usefulness, as previous work suggests different species may have unique regulatory mechanisms, even for similar catabolic genes (Moreno and Rojo, 2019). More effort is needed to overcome a bias in the literature towards $\mathrm{C}_{5}-\mathrm{C}_{18}$ alkane sensing systems and AlkB or CYP enzymes; this has led to a neglect of the systems responding to smaller alkanes and alkenes, especially those associated with SDIMOs and CuMMOs. Investing in research on thorough characterisation of regulatory systems will give increased understanding of how these systems function in nature, leading to better biosensors, and also helping to remove legal barriers to implementation in the field.

Very few hydrocarbon regulatory systems have met all five proposed criteria for complete characterisation (van der Meer and Belkin, 2010), and these knowledge gaps will limit the development of biosensors. The complexities of these systems should not be underestimated, and much more research is required to appreciate their intricacies. Untangling the regulation of different hydrocarbon catabolic genes that exist 
within a single strain is an especially useful avenue to pursue (Coleman et al., 2011a); this will give insights into the behaviour of biosensor circuits which must function in the presence of other hydrocarbon catabolic genes and regulators, and will inform the construction of more complex systems that integrate multiple sensing systems into a single cell.

Continued research attempts at the proof-of-concept stage of hydrocarbon biosensors are also warranted. This may involve directed evolution or site-specific modifications of regulatory components to yield biosensors with improved qualities, or proceeding with wild-type sensor systems, many of which already have good sensitivity and specificity (van der Meer and Belkin, 2010). Challenges at the proof-of-concept stage are often due to issues with robustness, shelf-life, and applicability to different real-world environments (Hicks et al., 2020) e.g., how to safely immobilise the cells while maintaining their function. Investigation into the localisation of wild type regulatory proteins could also be valuable, as it can influence the response time of the biosensor (Ding et al., 2021).

Three specific recommendations for research can be drawn from this review (Figure 5). Firstly, there are already two excellent octane biosensors, the plasmid-based $A l k S / P_{\text {alkB }} / \mathrm{GFP}$ biosensor in $E$. coli DH10ß (Reed et al., 2012) and the chromosomal alkR/P alkM $/$ luxAB sensor in A. baylyi (Zhang et al., 2011; Zhang et al., 2012a; Li et al., 2013); these are ready to progress to the final stage of development and deployment, which should focus on testing their robustness, sensitivity and selectivity in various real-world environments, and on finding the best methods of immobilising or encapsulating the cells. Secondly, several medium-chain alkane biosensor systems that work well in the lab (Zhang et al., 2012b; Sevilla et al., 2015) should now be progressed to the optimisation stages, e.g. to make a suite of sensors, each with selectivity for different single analytes. Finally, the molecular details of alkene-sensing systems need to be much

\section{REFERENCES}

Alonso, H., and Roujeinikova, A. (2012). Characterization and TwoDimensional Crystallization of Membrane Component AlkB of the Medium-Chain Alkane Hydroxylase System from Pseudomonas Putida GPo1. Appl. Environ. Microbiol. 78 (22), 7946-7953. doi:10.1128/ AEM.02053-12

Anantharaman, V., and Aravind, L. (2005). MEDS and PocR Are Novel Domains with a Predicted Role in Sensing Simple Hydrocarbon Derivatives in Prokaryotic Signal Transduction Systems. Bioinformatics 21 (12), 2805-2811. doi:10.1093/ bioinformatics/bti418

Arenghi, F. L. G., Barbieri, P., Bertoni, G., and de Lorenzo, V. (2001). New Insights into the Activation of $\mathrm{O}$-xylene Biodegradation in Pseudomonas Stutzeri OX1 by Pathway Substrates. EMBO Rep. 2 (5), 409-414. doi:10.1093/EMBOREPORTS/KVE092

Arenghi, F. L. G., Pinti, M., Galli, E., and Barbieri, P. (1999). Identification of the Pseudomonas Stutzeri OX1 Toluene- O -Xylene Monooxygenase Regulatory Gene (touR) and of its Cognate Promoter. Appl. Environ. Microbiol. 65 (9), 4057-4063. doi:10.1128/AEM.65.9.4057-4063.1999

Arroyo-Olarte, R. D., Bravo Rodríguez, R., Morales-Ríos, E., and Morales-Ríos, E. (2021). Genome Editing in Bacteria: CRISPR-Cas and beyond. Microorganisms 9 (4), 844. doi:10.3390/MICROORGANISMS9040844

Banerjee, R., Jones, J. C., and Lipscomb, J. D. (2019). Soluble Methane Monooxygenase, Annual Review of Biochemistry 88, 409-431. doi:10.1146/ annurev-biochem-013118-111529 better characterised, since our understanding of these is still rudimentary.

New developments in synthetic biology have greatly expanded the possibilities for hydrocarbon biosensors. The combination of synthetic biology methods with the wealth of novel sequences that continue to appear in genetic databases promises an exciting future for this research field. However, to maximise these possibilities our efforts must be effectively targeted at the appropriate development stages for each biosensor. Making successful commercial biosensors for deployment in real environmental or industrial contexts will require genuinely interdisciplinary efforts including microbiologists, molecular biologists, biochemists, structural biologists, engineers, materials scientists, and mathematical modellers. The microbes have provided the raw materials, but now we must provide the ingenuity and the effort to complete these tasks.

\section{AUTHOR CONTRIBUTIONS}

$\mathrm{CM}, \mathrm{NC}$, and CS contributed to the design of this review and defined the scope. CM carried out the main data collection and analysis. CM and NC drafted the manuscript. NC and CS provided critical revision of the draft.

\section{FUNDING}

This research is funded by a Research Training Program scholarship provided by the Australian Government, with additional financial, technical, and supervisory support from the CSIRO Future Science Platform in Synthetic Biology.

Baptist, J. N., Gholson, R. K., and Coon, M. J. (1963). Hydrocarbon Oxidation by a Bacterial Enzyme System. Biochim. Biophys. Acta 69, 40-47. doi:10.1016/00063002(63)91223-x

Bjerketorp, J., Håkansson, S., Belkin, S., and Jansson, J. K. (2006). Advances in Preservation Methods: Keeping Biosensor Microorganisms Alive and Active. Curr. Opin. Biotechnol. 17 (1), 43-49. doi:10.1016/J.COPBIO.2005.12.005

Boase-Beier, J., Fawcett, A., Wilson, P., and Schauer, F. (2014). Introduction. AMB Express 4 (1), 1-10. doi:10.1186/S13568-014-0075-2

Broberg, C. A., and Clark, D. D. (2010). Shotgun Proteomics of Xanthobacter Autotrophicus Py2 Reveals Proteins Specific to Growth on Propylene. Arch. Microbiol. 192 (11), 945-957. doi:10.1007/s00203-010-0623-3

Browning, D. F., and Busby, S. J. W. (2016). Local and Global Regulation of Transcription Initiation in Bacteria. Nat. Rev. Microbiol. 14, 638-650. doi:10.1038/nrmicro.2016.103

Buck, M., and Cannon, W. (1992). Specific Binding of the Transcription Factor Sigma-54 to Promoter DNA. Nature 358 (6385), 422. doi:10.1038/358422A0

Burrows, K. J., Cornish, A., Scott, D., and Higgins, I. J. (1984). Substrate Specificities of the Soluble and Particulate Methane Mono-Oxygenases of Methylosinus Trichosporium OB3b. Microbiology 130 (12), 3327-3333. doi:10.1099/00221287-130-12-3327

Canosa, I., Sanchez-Romero, J. M., Yuste, L., and Rojo, F. (2000). A Positive Feedback Mechanism Controls Expression of AlkS, the Transcriptional Regulator of the Pseudomonas Oleovorans Alkane Degradation Pathway. Mol. Microbiol. 35 (4), 791-799. doi:10.1046/j.1365-2958.2000.01751.x

Cappelletti, M., Fedi, S., Frascari, D., Ohtake, H., Turner, R. J., and Zannoni, D. (2011). Analyses of Both the alkB Gene Transcriptional Start Site and alkB 
Promoter-Inducing Properties of Rhodococcus Sp. Strain BCP1 Grown on N -Alkanes. Appl. Environ. Microbiol. 77 (5), 1619-1627. doi:10.1128/ AEM.01987-10

Cappelletti, M., Presentato, A., Milazzo, G., Turner, R. J., Fedi, S., Frascari, D., et al. (2015). Growth of Rhodococcus Sp. Strain BCP1 on Gaseous N-Alkanes: New Metabolic Insights and Transcriptional Analysis of Two Soluble Di-iron Monooxygenase Genes. Front. Microbiol. 6, 393. doi:10.3389/fmicb.2015.00393

Carpenter, A., Paulsen, I., and Williams, T. (2018). Blueprints for Biosensors: Design, Limitations, and Applications. Genes 9, 375-403. doi:10.3390/ genes 9080375

Cerniglia, C. E., and Crow, S. A. (1981). Metabolism of Aromatic Hydrocarbons by Yeasts. Arch. Microbiol. 129 (1), 9-13. doi:10.1007/BF00417170

Champreda, V., Zhou, N.-Y., and Leak, D. J. (2004). Heterologous Expression of Alkene Monooxygenase Components fromXanthobacter autotrophicusPy2 and Reconstitution of the Active Complex. FEMS Microbiol. Lett. 239 (2), 309-318. doi:10.1016/j.femsle.2004.09.002

Chauhan, A., Fazlurrahman, J. G. O., Oakeshott, J. G., and Jain, R. K. (2008). Bacterial Metabolism of Polycyclic Aromatic Hydrocarbons: Strategies for Bioremediation. Indian J. Microbiol. 48 (1), 95-113. doi:10.1007/S12088008-0010-9

Cheung, S., McCarl, V., Holmes, A. J., Coleman, N. V., and Rutledge, P. J. (2013). Substrate Range and Enantioselectivity of Epoxidation Reactions Mediated by the Ethene-Oxidising Mycobacterium Strain NBB4. Appl. Microbiol. Biotechnol. 97 (3), 1131-1140. doi:10.1007/s00253-012-3975-6

Chuang, A. S., JinJin, Y. O. L., Schmidt, L. S., Li, Y., Fogel, S., Smoler, D., et al. (2010). Proteomic Analysis of Ethene-Enriched Groundwater Microcosms from a Vinyl Chloride-Contaminated Site. Environ. Sci. Technol. 44 (5), 1594-1601. doi:10.1021/es903033r

Chuang, A. S., and Mattes, T. E. (2007). Identification of Polypeptides Expressed in Response to Vinyl Chloride, Ethene, and Epoxyethane in Nocardioides Sp. Strain JS614 by Using Peptide Mass Fingerprinting. Appl. Environ. Microbiol. 73 (13), 4368-4372. doi:10.1128/AEM.00086-07

Coleman, N. V., Bui, N. B., and Holmes, A. J. (2006). Soluble Di-iron Monooxygenase Gene Diversity in Soils, Sediments and Ethene Enrichments. Environ. Microbiol. 8 (7), 1228-1239. doi:10.1111/j.14622920.2006.01015.x

Coleman, N. V., Le, N. B., Ly, M. A., Ogawa, H. E., McCarl, V., Wilson, N. L., et al. (2012). Hydrocarbon Monooxygenase in Mycobacterium: Recombinant Expression of a Member of the Ammonia Monooxygenase Superfamily. Isme J. 6 (1), 171-182. doi:10.1038/ismej.2011.98

Coleman, N. V., and Spain, J. C. (2003a). Distribution of the Coenzyme M Pathway of Epoxide Metabolism Among Ethene- and Vinyl Chloride-Degrading Mycobacterium Strains. Appl. Environ. Microbiol. 69 (10), 6041-6046. doi:10.1128/AEM.69.10.6041-6046.2003

Coleman, N. V., and Spain, J. C. (2003b). Epoxyalkane:Coenzyme M Transferase in the Ethene and Vinyl Chloride Biodegradation Pathways of Mycobacterium Strain JS60. J. Bacteriol. 185 (18), 5536-5545. doi:10.1128/JB.185.18.55365545.2003

Coleman, N. V., Wilson, N. L., Barry, K., Brettin, T. S., Bruce, D. C., Copeland, A., et al. (2011b). Genome Sequence of the Ethene- and Vinyl Chloride-Oxidizing Actinomycete Nocardioides Sp. Strain JS614. J. Bacteriol. 193 (13), 3399-3400. doi:10.1128/JB.05109-11

Coleman, N. V., Yau, S., Wilson, N. L., Nolan, L. M., Migocki, M. D. D., Ly, M.-a., et al. (2011a). Untangling the Multiple Monooxygenases ofMycobacterium Chubuensestrain NBB4, a Versatile Hydrocarbon Degrader. Environ. Microbiol. Rep. 3 (3), 297-307. doi:10.1111/j.1758-2229.2010.00225.x

Coscolín, C., Bargiela, R., Martínez-Martínez, M., Alonso, S., Bollinger, A., Thies, S., et al. (2019). "Hydrocarbon-Degrading Microbes as Sources of New Biocatalysts," in Taxonomy, Genomics and Ecophysiology of HydrocarbonDegrading Microbes (Cham: Springer), 353-373. doi:10.1007/978-3-03014796-9_13

Crombie, A. T., Khawand, M. E., Rhodius, V. A., Fengler, K. A., Miller, M. C., Whited, G. M., et al. (2015). Regulation of Plasmid-encoded Isoprene Metabolism in R Hodococcus, a Representative of an Important Link in the Global Isoprene Cycle. Environ. Microbiol. 17 (9), 3314-3329. doi:10.1111/ $1462-2920.12793$

Cuthbertson, L., and Nodwell, J. R. (2013). The TetR Family of Regulators. Microbiol. Mol. Biol. Rev. 77 (3), 440-475. doi:10.1128/MMBR.00018-13
Cybulski, L. E., del Solar, G., Craig, P. O., Espinosa, M., and de Mendoza, D. (2004). Bacillus Subtilis DesR Functions as a Phosphorylation-Activated Switch to Control Membrane Lipid Fluidity. J. Biol. Chem. 279 (38), 39340-39347. doi:10.1074/JBC.M405150200

Das, N., and Chandran, P. (2011). Microbial Degradation of Petroleum Hydrocarbon Contaminants: An Overview. Biotechnol. Res. Int. 2011 (941810), 1-13. doi:10.4061/2011/941810

Das, S., Pettersson, B. M. F., Behra, P. R. K., Ramesh, M., Dasgupta, S., Bhattacharya, A., et al. (2015). Characterization of ThreeMycobacteriumspp. With Potential Use in Bioremediation by Genome Sequencing and Comparative Genomics. Genome Biol. Evol. 7 (7), 1871-1886. doi:10.1093/ gbe/evv111

de las Heras, A., and de Lorenzo, V. (2012). "Engineering Whole-Cell Biosensors with No Antibiotic Markers for Monitoring Aromatic Compounds in the Environment," in Methods in Molecular Biology (New York, NY: Springer), 261-281. doi:10.1007/978-1-61779-483-4_17

de las Heras, A., and de Lorenzo, V. (2010). "Genetic Constructs: Molecular Tools for the Assembly of Environmental Bacterial Biosensors," in Handbook of Hydrocarbon and Lipid Microbiology (Berlin, Heidelberg; Springer), 2651-2676. doi:10.1007/978-3-540-77587-4_197

Deng, D., Li, F., and Li, M. (2018). A Novel Propane Monooxygenase Initiating Degradation of 1,4-Dioxane by Mycobacterium Dioxanotrophicus PH-06. Environ. Sci. Technol. Lett. 5 (2), 86-91. doi:10.1021/acs.estlett.7b00504

Dietrich, J. A., Shis, D. L., Alikhani, A., and Keasling, J. D. (2012). Transcription Factor-Based Screens and Synthetic Selections for Microbial Small-Molecule Biosynthesis. ACS Synth. Biol. 2, 47-58. doi:10.1021/sb300091d

Dietrich, J. A. (2011). Transcription Factor-Based Small-Molecule Screens and Selections. Berkeley, California; University of California.

Dinamarca, M. A., Aranda-Olmedo, I., Puyet, A., and Rojo, F. (2003). Expression of the Pseudomonas Putida OCT Plasmid Alkane Degradation Pathway Is Modulated by Two Different Global Control Signals: Evidence from Continuous Cultures. J. Bacteriol. 185 (16), 4772-4778. doi:10.1128/ JB.185.16.4772-4778.2003

Ding, N., Zhou, S., and Deng, Y. (2021). Transcription-Factor-Based Biosensor Engineering for Applications in Synthetic Biology. ACS Synth. Biol. 10, 911-922. doi:10.1021/ACSSYNBIO.0C00252

Diplock, E. E., Alhadrami, H. A., and Paton, G. I. (2010). "Commercial Application of Bioluminescence Full Cell Bioreporters for Environmental Diagnostics," in Handbook of Hydrocarbon and Lipid Microbiology (Berlin Heidelberg; Springer), 4445-4458. doi:10.1007/978-3-540-77587-4_347

Dong, C., Fontana, J., Patel, A., Carothers, J. M., and Zalatan, J. G. (2018). Synthetic CRISPR-Cas Gene Activators for Transcriptional Reprogramming in Bacteria. Nat. Commun. 9 (1), 1-11. doi:10.1038/s41467-018-04901-6

Doughty, D. M., Sayavedra-Soto, L. A., Arp, D. J., and Bottomley, P. J. (2006). Product Repression of Alkane Monooxygenase Expression in Pseudomonas Butanovora. J. Bacteriol. 188 (7), 2586-2592. doi:10.1128/JB.188.7.25862592.2006

D’Souza, S. F. (2001). Review: Microbial Biosensors. Biosens. Bioelectron. 16, 337-353. https://pdf.sciencedirectassets.com/271399/1-s2.0-S0956566300X00553/1 -s2.0-S0956566301001257/main.pdf?x-amz-security-token=AgoJb3JpZ2luX2 VjEHMaCXVzLWVhc3QtMSJHMEUCIFBeIFmvxw\%2FbtYnnrfnDB4\% 2BjRUkzFYpwl5jDAjKIeZ99AiEAmcbYl0vgtsMfuilQKx74NCccMNsm4xdi4UH lYMJ0.

Dubbels, B. L., Sayavedra-Soto, L. A., and Arp, D. J. (2007). Butane Monooxygenase of 'Pseudomonas Butanovora': Purification and Biochemical Characterization of a Terminal-Alkane Hydroxylating Diiron Monooxygenase. Microbiology 153 (6), 1808-1816. doi:10.1099/mic.0.2006/004960-0

Ensign, S. A. (1996). Aliphatic and Chlorinated Alkenes and Epoxides as Inducers of Alkene Monooxygenase and Epoxidase Activities in Xanthobacter Strain Py2. Appl. Environ. Microbiol. 62 (1), 61-66. doi:10.1128/aem.62.1.61-66.1996

Ensign, S. A., Hyman, M. R., and Arp, D. J. (1992). Cometabolic Degradation of Chlorinated Alkenes by Alkene Monooxygenase in a Propylene-Grown Xanthobacter Strain. Appl. Environ. Microbiol. 58 (9), 3038-3046. doi:10.1128/aem.58.9.3038-3046.1992

Ensign, S. A. (2001). Microbial Metabolism of Aliphatic Alkenes. Biochemistry 40 (20), 5845-5853. doi:10.1021/bi015523d 
Feng, L., Wang, W., Cheng, J., Ren, Y., Zhao, G., Gao, C., et al. (2007). Genome and Proteome of Long-Chain Alkane Degrading Geobacillus Thermodenitrificans NG80-2 Isolated from a Deep-Subsurface Oil Reservoir. Proc. Natl. Acad. Sci. 104 (13), 5602-5607. doi:10.1073/pnas.0609650104

Fiorentini, F., Hatzl, A.-M., Schmidt, S., Savino, S., Glieder, A., and Mattevi, A. (2018). The Extreme Structural Plasticity in the CYP153 Subfamily of P450s Directs Development of Designer Hydroxylases. Biochemistry 57 (48), 6701-6714. doi:10.1021/ACS.BIOCHEM.8B01052

Francke, C., Groot Kormelink, T., Hagemeijer, Y., Overmars, L., Sluijter, V., Moezelaar, R., et al. (2011). Comparative Analyses Imply that the Enigmatic Sigma Factor 54 Is a Central Controller of the Bacterial Exterior. BMC Genomics 12 (385), 1-21. doi:10.1186/1471-2164-12-385

Fuqua, C., Winans, S. C., and Greenberg, E. P. (1996). Census and Consensus in Bacterial Ecosystems: The LuxR-LuxI Family of Quorum-Sensing Transcriptional Regulators. Annu. Rev. Microbiol. 50 (November), 727-751. doi:10.1146/ANNUREV.MICRO.50.1.727

Gacesa, R., Baranasic, D., Baranasic, D., Starcevic, A., Diminic, J., Korlević, M., et al. (2018). Bioprospecting for Genes Encoding HydrocarbonDegrading Enzymes from Metagenomic Samples Isolated from Northern Adriatic Sea Sediments. Food Technol. Biotechnol. 56 (2), 270-277. doi:10.17113/ftb.56.02.18.5393

Gallagher, S. C., Cammack, R., and Dalton, H. (1997). Alkene Monooxygenase from Nocardia Corallina B-276 Is a Member of the Class of Dinuclear Iron Proteins Capable of Stereospecific Epoxygenation Reactions. Eur. J. Biochem. 247 (2), 635-641. doi:10.1111/j.1432-1033.1997.00635.x

Gallagher, S. C., George, A., and Dalton, H. (1998). Sequence-alignment Modelling and Molecular Docking Studies of the Epoxygenase Component of Alkene Monooxygenase from Nocardia Corallina B-276. Eur. J. Biochem. 254, 480-489. doi:10.1046/j.1432-1327.1998.2540480.x

Gallegos, M. T., Schleif, R., Bairoch, A., Hofmann, K., and Ramos, J. L. (1997). Arac/XylS Family of Transcriptional Regulators. Microbiol. Mol. Biol. Rev. MMBR 61 (4), 393-410. doi:10.199710.1128/61.4.393-410.1997

Galvão, T. C., de Lorenzo, V., and De Lorenzo, V. (2006). Transcriptional regulators à la carte: engineering new effector specificities in bacterial regulatory proteins. Curr. Opin. Biotechnol. 17, 34-42. doi:10.1016/ j.copbio.2005.12.002

Ginkel, C. G. v. (1987). Oxidation of Gaseous Hydrocarbons by Alkene-Utilizing Bacteria. Wageningen, Netherlands; Wageningen University \& Research.

Ginkel, C. G. V., Welten, H. G. J., and De Bont, J. A. M. (1987). Oxidation of Gaseous and Volatile Hydrocarbons by Selected Alkene-Utilizing Bacteria, Appl Environ Microbiol 53. 2903-2907. doi:10.1128/ aem.53.12.2903-2907.1987

Grant, C., Deszcz, D., Wei, Y.-C., Martínez-Torres, R. J., Morris, P., Folliard, T., et al. (2014). Identification and Use of an Alkane Transporter Plug-In for Applications in Biocatalysis and Whole-Cell Biosensing of Alkanes. Sci. Rep. 4 (5844). doi:10.1038/srep05844

Hannon, G. J. (2002). RNA Interference. Nature 418 (6894), 244-251. doi:10.1038/ $418244 \mathrm{a}$

Hanson, R. S., and Hanson, T. E. (1996). Methanotrophic Bacteria. Microbiol. Rev. 60 (2), 439-471. doi:10.1128/mr.60.2.439-471.1996

Harayama, S., Kasai, Y., and Hara, A. (2004). Microbial Communities in OilContaminated Seawater. Curr. Opin. Biotechnol. 15, 205-214. doi:10.1016/ j.copbio.2004.04.002

Harms, H., Wells, M. C., and Van Der Meer, J. R. (2006). Whole-cell Living Biosensors-Are They Ready for Environmental Application. Appl. Microbiol. Biotechnol. 70 (3), 273-280. doi:10.1007/s00253-006-0319-4

Harrison, S. C. (1991). A Structural Taxonomy of DNA-Binding Domains. Nature 353, 715-719. doi:10.1038/353715a0

Hicks, M., Bachmann, T. T., and Wang., B. (2020). Synthetic Biology Enables Programmable Cell-Based Biosensors. ChemPhysChem 21 (2), 132-144. doi:10.1002/cphc.201900739

Holmes, A. J., and Coleman., N. V. (2008). Evolutionary Ecology and Multidisciplinary Approaches to Prospecting for Monooxygenases as Biocatalysts. Antonie van Leeuwenhoek 94 (1), 75-84. doi:10.1007/s10482-008-9227-1

Huang, W. E., Li, C., Zhang, D., Song, Y., Jiang, B., Li, G., et al. (2013). Whole Cell Bioreporter for the Estimation of Oil Contamination. Environ. Eng. Manag. J. 12 (7), 1353-1358. doi:10.30638/eemj.2013.166
Janssen, S., Schmitt, K., Blanke, M. J. W., Bauersfeld, M. L., Wöllenstein, J., and Lang, W. (2014). Ethylene Detection in Fruit Supply Chains. Phil. Trans. R. Soc. A. 372, 20130311. doi:10.1098/rsta.2013.0311

Jaspers, M. C. M., Meier, C., Zehnder, A. J. B., Harms, H., and van der MeerVan der Meer, J. R. (2001). Measuring Mass Transfer Processes of Octane with the Help of an alkSalkB::gfp-Tagged Escherichia coli. Environ. Microbiol. 3 (8), 512-524. doi:10.1046/j.1462-2920.2001.00218.x

Ji, N., Wang, X., Yin, C., Peng, W., and Liang, R. (2019). CrgA Protein Represses AlkB2 Monooxygenase and Regulates the Degradation of Medium-To-LongChain N-Alkanes in Pseudomonas Aeruginosa SJTD-1. Front. Microbiol. 10 (March). doi:10.3389/fmicb.2019.00400

Ji, N., Wang, X., Yin, C., Peng, W., Liang, R., Wang, X., et al. (2019). CrgA Protein Represses AlkB2 Monooxygenase and Regulates the Degradation of MediumTo-Long-Chain N-Alkanes in Pseudomonas aeruginosa SJTD-1, Front. Microbiol. 10. doi:10.3389/fmicb.2019.00400

Jiang, B., Song, Y., Liu, Z., Huang, W. E., Li, G., Deng, S., et al. (2020). Whole-Cell Bioreporters for Evaluating Petroleum Hydrocarbon Contamination. Crit. Rev. Environ. Sci. Tech. 51, 272-322. doi:10.1080/10643389.2020.1717907

Johnson, E. L., and Hyman, M. R. (2006). Propane and N -Butane Oxidation by Pseudomonas Putida GPo1. Appl. Environ. Microbiol. 72 (1), 950-952. doi:10.1128/AEM.72.1.950-952.2006

Johnson, E. L., SmithO'Reilly, C. A. K. T., O’Reilly, K. T., and Hyman, M. R. (2004). Induction of Methyl Tertiary Butyl Ether (MTBE)-Oxidizing Activity in Mycobacterium Vaccae JOB5 by MTBE. Appl. Environ. Microbiol. 70 (2), 1023-1030. doi:10.1128/AEM.70.2.1023-1030.2004

Khadka, R., Clothier, L., Wang, L., Lim, C. K., Klotz, M. G., and Dunfield, P. F. (2018). Evolutionary History of Copper Membrane Monooxygenases. Front. Microbiol. 9, 2493. doi:10.3389/fmicb.2018.02493

Kim, D. H., and Rossi, J. J. (2008). RNAi Mechanisms and Applications. BioTechniques 44 (5), 613-616. doi:10.2144/000112792

Kok, M., Oldenhuis, R., Van Der Linden, M. P. G., Raatjes, P., Kingma, J., Van Lelyveld, P. H., et al. (1989). The Pseudomonas Oleovorans Alkane Hydroxylase Gene. J. Biol. Chem. 264 (10), 54354441. doi:10.1016/s00219258(18)83564-5

Kotani, T., Kawashima, Y., Yurimoto, H., Kato, N., and Sakai, Y. (2006). Gene Structure and Regulation of Alkane Monooxygenases in Propane-Utilizing Mycobacterium Sp. TY-6 and Pseudonocardia Sp. TY-7. J. Biosci. Bioeng. 102 (3), 184-192. doi:10.1263/jbb.102.184

Kotani, T., Yamamoto, T., Yurimoto, H., Sakai, Y., and Kato, N. (2003). PropaneMonooxygenase and NAD + -Dependent Secondary AlcoholDehydrogenase in Propane Metabolism by Gordonia sp.StrainTY-5. J. Bacteriol. 185 (24), 7120-7128. doi:10.1128/JB.185.24.7120-7128.2003

Kotani, T., Yurimoto, H., Kato, N., and Sakai, Y. (2007). Novel Acetone Metabolism in a Propane-Utilizing Bacterium, Gordonia Sp. Strain TY-5. J. Bacteriol. 189 (3), 886-893. doi:10.1128/JB.01054-06

Kumari, R., Tecon, R., Beggah, S., Rutler, R., Arey, J. S., and van der Meervan der Meer, J. R. (2011). Development of Bioreporter Assays for the Detection of Bioavailability of Long-Chain Alkanes Based on the Marine Bacterium Alcanivorax Borkumensis Strain SK2. Environ. Microbiol. 13 (10), 2808-2819. doi:10.1111/j.1462-2920.2011.02552.x

Kurth, E. G., Doughty, D. M., Bottomley, P. J., Arp, D. J., and Sayavedra-Soto, L. A. (2008). Involvement of BmoR and BmoG in N-Alkane Metabolism in 'Pseudomonas Butanovora'. Microbiology 154 (1), 139-147. doi:10.1099/ mic.0.2007/012724-0

Lazar, J. T., and Tabor, J. J. (2021). Bacterial Two-Component Systems as Sensors for Synthetic Biology Applications. Curr. Opin. Syst. Biol. 28, 100398. doi:10.1016/j.coisb.2021.100398

Lehtinen, T., Santala, V., and Santala, S. (2017). Twin-Layer Biosensor for RealTime Monitoring of Alkane Metabolism. FEMS Microbiol. Lett. 364 (6), 1-7. doi:10.1093/femsle/fnx053

Li, H., Wang, X.-L., Mu, B.-Z., Gu, J.-D., Liu, Y.-D., Lin, K.-F., et al. (2013). Molecular Detection, Quantification and Distribution of AlkaneDegrading Bacteria in Production Water from Low Temperature Oilfields. Int. Biodeterioration Biodegradation 76 (SI), 49-57. doi:10.1016/j.ibiod.2012.06.007

Li, L., Liu, X., Yang, W., Xu, F., Wang, W., Feng, L., et al. (2008). Crystal Structure of Long-Chain Alkane Monooxygenase (LadA) in Complex with Coenzyme 
FMN: Unveiling the Long-Chain Alkane Hydroxylase. J. Mol. Biol. 376 (2), 453-465. doi:10.1016/j.jmb.2007.11.069

Liang, J.-L., JiangYang, J.-H., Nie, Y., and Wu, X.-L. (2016a). Regulation of the Alkane Hydroxylase CYP153 Gene in a Gram-Positive Alkane-Degrading Bacterium, Dietzia Sp. Strain DQ12-45-1b. Appl. Environ. Microbiol. 82 (2), 608-619. doi:10.1128/AEM.02811-15

Liang, J.-L., Nie, Y., Wang, M., Xiong, G., Wang, Y.-P., Maser, E., et al. (2016b). Regulation of Alkane Degradation Pathway by a TetR Family Repressor via an Autoregulation Positive Feedback Mechanism in a GrampositiveDietziabacterium. Mol. Microbiol. 99 (2), 338-359. doi:10.1111/ mmi. 13232

Liang, J. L., Gao, Y., He, Z., Nie, Y., Wang, M., JiangYang, J. H., et al. (2017). Crystal Structure of TetR Family Repressor AlkX from Dietzia Sp. Strain DQ12-45-1b Implicated in Biodegradation of N-Alkanes. Appl. Environ. Microbiol. 83 (21), 1-15. doi:10.1128/AEM.01447-17

Lieberman, R. L., and Rosenzweig, A. C. (2004). Biological Methane Oxidation: Regulation, Biochemistry, and Active Site Structure of Particulate Methane Monooxygenase. Crit. Rev. Biochem. Mol. Biol. 39 (3), 147-164. doi:10.1080/ 10409230490475507

Liu, C., Wang, W., Wu, Y., Zhou, Z., Lai, Q., and Shao, Z. (2011). Multiple Alkane Hydroxylase Systems in a Marine Alkane Degrader, Alcanivorax Dieselolei B-5. Environ. Microbiol. 13 (5), 1168-1178. doi:10.1111/j.14622920.2010.02416.x

Liu, H., Xu, J., Liang, R., and Liu, J. (2014). Characterization of the Medium- and Long-Chain N-Alkanes Degrading Pseudomonas aeruginosa Strain SJTD-1 and its Alkane Hydroxylase Genes. Plos One 9 (8), e105506. doi:10.1371/ journal.pone.0105506

Liu, X., Germaine, K. J., Ryan, D., and Dowling, D. N. (2007). Development of a Gfp-based Biosensor for Detecting the Bioavailability and Biodegradation of Polychlorinated Biphenyls (Pcbs). J. Environ. Eng. Landscape Manage. 15 (4), 261-268. doi:10.3846/16486897.2007.9636939

Lönneborg, R., Smirnova, I., Dian, C., Leonard, G. A., and Brzezinski, P. (2007). In Vivo and In Vitro Investigation of Transcriptional Regulation by DntR. J. Mol. Biol. 372 (3), 571-582. doi:10.1016/j.jmb.2007.06.076

Maeng, J. H., Sakai, Y., Tani, Y., and Kato, N. (1996). Isolation and Characterization of a Novel Oxygenase that Catalyzes the First Step of N-Alkane Oxidation in Acinetobacter Sp. Strain M-1. J. Bacteriol. 178, 3695-3700. doi:10.1128/jb.178.13.3695-3700.1996

Marı'n, M. M., SmitsSmits, T. H., van Beilen, J. B., and Rojo, F. (2001). The Alkane Hydroxylase Gene of Burkholderia Cepacia RR10 Is under Catabolite Repression Control. J. Bacteriol. 183 (14), 4202-4209. doi:10.1128/ JB.183.14.4202-4209.2001

Mari'n, M. M., Yuste, L., and Rojo, F. (2003). Differential Expression of the Components of the Two Alkane Hydroxylases from Pseudomonas Aeruginosa. J. Bacteriol. 185 (10), 3232-3237. doi:10.1128/JB.185.10.3232-3237.2003

Martin, K. E., Ozsvar, J., and Coleman, N. V. (2014). SmoXYB1C1Z of Mycobacterium Sp. Strain NBB4: a Soluble Methane Monooxygenase (sMMO)-like Enzyme, Active on C2to C4Alkanes and Alkenes. Appl. Environ. Microbiol. 80 (18), 5801-5806. doi:10.1128/AEM.01338-14

Mattes, T. E., Alexander, A. K., and Coleman, N. V. (2010). Aerobic Biodegradation of the Chloroethenes: Pathways, Enzymes, Ecology, and Evolution. FEMS Microbiol. Rev. 34 (4), 445-475. doi:10.1111/j.1574-6976.2010.00210.x

Mattes, T. E., ColemanColeman, N. V. J. C. S., Spain, J. C., and Gossett, J. M. (2005). Physiological and Molecular Genetic Analyses of Vinyl Chloride and Ethene Biodegradation in Nocardioides Sp. Strain JS614. Arch. Microbiol. 183 (2), 95-106. doi:10.1007/s00203-004-0749-2

McCarl, V., Somerville, M. V., LyLy, M. A., Henry, R., Liew, E. F., Wilson, N. L., et al. (2018). Heterologous Expression of Mycobacterium Alkene Monooxygenases in Gram-Positive and Gram-Negative Bacterial Hosts. Appl. Environ. Microbiol. 84 (15), 1-16. doi:10.1128/AEM.00397-18

Minak-Bernero, V., Bare, R. E., Haith, C. E., and Grossman, M. J. (2004). Detection of Alkanes, Alcohols, and Aldehydes Using Bioluminescence. Biotechnol. Bioeng. 87 (2), 170-177. doi:10.1002/bit.20089

Minerdi, D., Sadeghi, S. J., Di Nardo, G., Rua, F., Castrignanò, S., Allegra, P., et al. (2015). CYP116B5: a New Class VII Catalytically Self-Sufficient Cytochrome P450 fromAcinetobacter Radioresistensthat Enables Growth on alkanesCYP116B5: A New Class VII Catalytically Self-Sufficient Cytochrome
P450 from A Cinetobacter Radioresistens that Enables Growth on Alkanes. Mol. Microbiol. 95 (3), 539-554. doi:10.1111/mmi.12883

Miuran, A., and Dalton, H. (1995). Purification and Characterization of the Alkene Monooxygenase fromNocardia corallinaB-276. Biosci. Biotechnol. Biochem. 59 (5), 853-859. doi:10.1271/bbb.59.853

Monterrubio, R., Baldoma, L., Obradors, N., Aguilar, J., and Badia, J. (2000). A Common Regulator for the Operons Encoding the Enzymes Involved in D-Galactarate, D-Glucarate, and D-Glycerate Utilization in Escherichia coli. J. Bacteriol. 182, 2672-2674. doi:10.1128/jb.182.9.2672-2674.2000

Moratti, C., Chen, A., Chen, S. Y., Douglas, S., Ferguson, L., Kyaw, W., et al. 2016. "Fruit Ripeness Ethylene Sensor (Hopefully)," In IGEM Giant Jamboree.

Moreno, R., and Rojo, F. (2017). "Enzymes for Aerobic Degradation of Alkanes in Bacteria," in Aerobic Utilization of Hydrocarbons, Oils and Lipids (Cham: Springer International Publishing), 1-25. doi:10.1007/978-3-319-39782-5_6-1

Moreno, R., and Rojo, F. (2019). "Genetic Features and Regulation of N-Alkane Metabolism in Bacteria," in Handbook Of Aerobic Utilitisation Of Hydrocarbons, Oils And Lipids. Editor F Rojo (Madrid: Springer Nature Switzerland), 521-542. doi:10.1007/978-3-319-50418-6_23

Morris, R. M., Nunn, B. L., Frazar, C., Goodlett, D. R. Y. S. T., Ting, Y. S., and Rocap, G. (2010). Comparative Metaproteomics Reveals Ocean-Scale Shifts in Microbial Nutrient Utilization and Energy Transduction. Isme J. 4 (5), 673-685. doi:10.1038/ismej.2010.4

Murrell, J. C., Gilbert, B., and McDonald, I. R. (2000). Molecular Biology and Regulation of Methane Monooxygenase. Arch. Microbiol. 173 (March), 325-332. doi:10.1007/s002030000158

Musumeci, M., Lozada, M., Rial, D., Mac Cormack, W., Jansson, J., Sjöling, S., et al. (2017). Prospecting Biotechnologically-Relevant Monooxygenases from Cold Sediment Metagenomes: An In Silico Approach. Mar. Drugs 15 (4), 114. doi: $10.3390 / \mathrm{md} 15040114$

Nandimandalam, H., Ghimire, U., and Veera Gnaneswar, G. (2018). Microbial Biosensors for the Early Detection and Prevention of Hydrocarbon Pipeline Releases. HDIAC J. 5 (3), 15-21.

Nie, Y., ChiChi, C.-Q., Fang, H., LiangLaiTang, J.-L., LuWu, S.-L., Lai, G.-L., et al. (2014a). Diverse Alkane Hydroxylase Genes in Microorganisms and Environments. Sci. Rep. 4, 1-11. doi:10.1038/srep04968

Nie, Y., Liang, J.-L., Fang, H., TangTang, Y.-Q., and WuWu, X.-L. (2014b). Characterization of a CYP153 Alkane Hydroxylase Gene in a Gram-Positive Dietzia Sp. DQ12-45-1b and its "team Role" with alkW1 in Alkane Degradation. Appl. Microbiol. Biotechnol. 98 (1), 163-173. doi:10.1007/s00253-013-4821-1

Ould Ali, N., Bignon, J., Rapoport, G., and Debarbouille, M. (2001). Regulation of the Acetoin Catabolic Pathway Is Controlled by Sigma L in Bacillus Subtilis. J. Bacteriol. 183 (8), 2497-2504. doi:10.1128/ JB.183.8.2497-2504.2001

Owens, C. R., Karceski, J. K., and Mattes, T. E. (2009). Gaseous Alkene Biotransformation and Enantioselective Epoxyalkane Formation by Nocardioides Sp. Strain JS614. Appl. Microbiol. Biotechnol. 84 (4), 685-692. doi:10.1007/s00253-009-2019-3

Paget, M. S., and Helmann, J. D. (2003). The Sigma70 Family of Sigma Factors. Genome Biol. 4 (203), 203. doi:10.1186/GB-2003-4-1-203

Panke, S., Meyer, A. C. M., Huber, C. M., Witholt, B., and Wubbolts, M. G. (1999). An Alkane-Responsive Expression System for the Production of Fine Chemicals. Appl. Environ. Microbiol. 65 (6), 2324-2332. doi:10.1128/ aem.65.6.2324-2332.1999

Plotnikova, E. G., Shumkova, E. S., and Shumkov, M. S. (2016). Whole-Cell Bacterial Biosensors for the Detection of Aromatic Hydrocarbons and Their Chlorinated Derivatives (Review). Appl. Biochem. Microbiol. 52 (4), 347-357. doi:10.1134/s0003683816040128

Prenafeta-Boldu, F, X., Sybren de Hoog, G., and Summerbell, R. C., and (2019). "Fungal Communities in Hydrocarbon Degradation," in Handbook Of Hydrocarbon And Lipid Microbiology. Editors T. J. Mcgenity (Switzerland; Springer Nature). doi:10.1007/978-3-030-14785-3_8

Prince, R. C. (2010). "Eukaryotic Hydrocarbon Degraders," in Handbook of Hydrocarbon And Lipid Microbiology. Editor K N. Timmis (Berlin, Heidelberg: Springer), 2065-2078. doi:10.1007/978-3-540-77587-4_150

Ratajczak, A., Geißdörfer, W., and Hillen, W. (1998a). Alkane Hydroxylase from Acinetobacter Sp. Strain ADP1 Is Encoded by AlkM and Belongs to a New Family of Bacterial Integral-Membrane Hydrocarbon Hydroxylases. 
Appl. Environ. Microbiol. 64 (4), 1175-1179. doi:10.1128/aem.64.4.11751179.1998

Ratajczak, A., Geißdörfer, W., and Hillen, W. (1998b). Expression of Alkane Hydroxylase from Acinetobacter Sp. Strain ADP1 Is Induced by a Broad Range of N-Alkanes and Requires the Transcriptional Activator AlkR. J. Bacteriol. 180 (22), 5822-5827. doi:10.1128/ jb.180.22.5822-5827.1998

Read, J. T., Cheng, H., Hendy, S. C., Nelson, C. C., and Rennie, P. S. (2009). Receptor-DNA Interactions: EMSA and Footprinting. Methods Mol. Biol. 505, 97-122. doi:10.1007/978-1-60327-575-0_6

Reed, B., Blazeck, J., and Alper, H. (2012). Evolution of an Alkane-Inducible Biosensor for Increased Responsiveness to Short-Chain Alkanes. J. Biotechnol. 158 (3), 75-79. doi:10.1016/J.JBIOTEC.2012.01.028

Reineke, W., Mandt, C., Kaschabek, S. R., and PieperPieper, D. H. (2020). Chlorinated Hydrocarbon Metabolism. ELS, 1-21. doi:10.1002/ 9780470015902.A0000472.PUB4

Rochman, F. F., Kwon, M., Khadka, R., Tamas, I., Lopez-Jauregui, A. A., Sheremet, A., et al. (2020). Novel Copper-Containing Membrane Monooxygenases (CuMMOs) Encoded by Alkane-Utilizing Betaproteobacteria. Isme J. 14 (3), 714-726. doi:10.1038/s41396-019-0561-2

Rojo, F. (2009). Degradation of Alkanes by Bacteria. Environ. Microbiol. 11 (10), 2477-2490. doi:10.1111/j.1462-2920.2009.01948.x

Rosenzweig, A. C., Frederick, C. A., Lippard, S. J., and Nordlund, P. a. r. (1993). Crystal Structure of a Bacterial Non-haem Iron Hydroxylase that Catalyses the Biological Oxidation of Methane. Nature 366, 537-543. doi: $10.1038 / 366537 \mathrm{a} 0$

Sadana, A., and Sadana, N. (2011). "Economics of Biosensors," in Handbook of Biosensors and Biosensor Kinetics. 1st ed. (United States: Elsevier Science), 487-505. doi:10.1016/b978-0-444-53262-6.00017-6

Saeki, H., and Furuhashi, K. (1994). Cloning and Characterization of a Nocardia Corallina B-276 Gene Cluster Encoding Alkene Monooxygenase. J. Ferment. Bioeng. 78 (6), 399-406. doi:10.1016/0922-338X(94)90037-X

Sakai, Y., Maeng, J. H. S. K., Kubota, S., Tani, A., Tani, Y., and Kato, N. (1996). A Non-conventional Dissimilation Pathway for Long Chain N-Alkanes in Acinetobacter Sp. M-1 that Starts with a Dioxygenase Reaction. JOURNAL Ferment. Bioeng. 81 (4), 286-291. doi:10.1016/0922-338X(96)80578-2

Sales, C. M., Grostern, A., ParalesParales, J. V., Parales, R. E., and Alvarez-Cohen, L. (2013). Oxidation of the Cyclic Ethers 1,4-Dioxane and Tetrahydrofuran by a Monooxygenase in Two Pseudonocardia Species. Appl. Environ. Microbiol. 79 (24), 7702-7708. doi:10.1128/AEM.02418-13

Santala, S., Karp, M., and Santala, V. (2012). Monitoring Alkane Degradation by Single BioBrick Integration to an Optimal Cellular Framework. ACS Synth. Biol. 1, 60-64. doi:10.1021/sb2000066

Santos, C. L., Correia-Neves, M., Moradas-Ferreira, P., and Mendes, M. V. (2012). A Walk into the LuxR Regulators of Actinobacteria: Phylogenomic Distribution and Functional Diversity. Plos One 7 (10), e46758. doi:10.1371/ JOURNAL.PONE.0046758

Schneiker, S., dos SantosMartins Dos Santos, V. A. M., Bartels, D., Bekel, T., Brecht, M., Buhrmester, J., et al. (2006). Genome Sequence of the Ubiquitous Hydrocarbon-Degrading Marine Bacterium Alcanivorax Borkumensis. Nat. Biotechnol. 24 (8), 997-1004. doi:10.1038/nbt1232

Schrijver, A. D., and De Mot, R. (1999). A Subfamily of MalT-Related ATPdependent Regulators in the LuxR Family. Microbiology Comment. 145, 1287. doi:10.1099/13500872-145-6-1287

Sevilla, E., Yuste, L., Moreno, R., and Rojo, F. (2017). Differential Expression of the threeAlcanivorax borkumensisSK2 Genes Coding for the P450 Cytochromes Involved in the Assimilation of Hydrocarbons. Environ. Microbiol. Rep. 9 (6), 797-808. doi:10.1111/1758-2229.12598

Sevilla, E., Yuste, L., and Rojo, F. (2015). Marine Hydrocarbonoclastic Bacteria as Whole-Cell Biosensors Forn-Alkanes. Microb. Biotechnol. 8 (4), 693-706. doi:10.1111/1751-7915.12286

Sharp, J. O., Sales, C. M., LeBlanc, J. C., LiuWood, J., Wood, T. K., Eltis, L. D., et al. (2007). An Inducible Propane Monooxygenase Is Responsible for $\mathrm{N}$ -Nitrosodimethylamine Degradation by Rhodococcus Sp. Strain RHA1. Appl. Environ. Microbiol. 73 (21), 6930-6938. doi:10.1128/AEM.01697-07

Shemer, B., and Belkin, S. (2019). "Microbial Biosensors for the Detection of Organic Pollutants," in Handbook Of Cell Biosensors. Editor Gerald Thouand (JerusalemCham: Springer), 1-24. doi:10.1007/978-3-319-47405-2_92-1
Shennan, J. L. (2006). Utilisation of C2-C4gaseous Hydrocarbons and Isoprene by Microorganisms. J. Chem. Technol. Biotechnol. 81 (3), 237-256. doi:10.1002/ jctb. 1388

Shingler, V. (2010). Experimental Evolution of Novel Regulatory Activities in Response to Hydrocarbons and Related Chemicals. Handbook Hydrocarbon Lipid Microbiol., 1235-1245. doi:10.1007/978-3-540-77587-4_86

Silva-Jiménez, H., García-Fontana, C., Cadirci, B. H., Ramos-González, M. I., Ramos, J. L., and Krell, T. (2012). Study of the TmoS/TmoT TwoComponent System: towards the Functional Characterization of the Family of TodS/TodT like Systems. Microb. Biotechnol. 5 (4), 489-500. doi:10.1111/J.1751-7915.2011.00322.X

Small, F. J., and Ensign, S. A. (1997). Alkene Monooxygenase from Xanthobacter Strain Py2. J. Biol. Chem. 272 (40), 24913-24920. doi:10.1074/jbc.272.40.24913

Smith, T. J., LloydGallagherMurrell, J. S., Gallagher, S. C., Fosdike, W. L. J., Murrell, J. C., and Dalton, H. (1999). Heterologous Expression of Alkene Monooxygenase from Rhodococcus Rhodochrous B-276. Eur. J. Biochem. 260 (2), 446-452. doi:10.1046/j.1432-1327.1999.00179.x

Smits, T. H. M., Balada, S. B., Witholt, B., and Van Beilen, J. B. (2002). Functional Analysis of Alkane Hydroxylases from Gram-Negative and Gram-Positive Bacteria. J. Bacteriol. 184 (6), 1733-1742. doi:10.1128/JB.184.6.1733-1742.2002

Smits, T. H. M., Rothlisberger, M., Witholt, B., and Van Beilen, J. B. (1999). Molecular Screening for Alkane Hydroxylase Genes in Gram-Negative and Gram-Positive Strains. Environ. Microbiol. 1 (4), 307-317. doi:10.1046/j.14622920.1999.00037.x

Smits, T. H. M., Witholt, B., and Van Beilen, J. B. (2003). Functional Characterization of Genes Involved in Alkane Oxidation by Pseudomonas Aeruginosa. Antonie van Leeuwenhoek 84 (3), 193-200. doi:10.1023/a: 1026000622765

Staijen, I. E., Marcionelli, R., and Witholt, B. (1999). The P alkBFGHJKL Promoter Is under Carbon Catabolite Repression Control in Pseudomonas Oleovorans but Not in Escherichia coli Alk + Recombinants. J. Bacteriol. 181 (5), 1610-1616. doi:10.1128/jb.181.5.1610-1616.1999

Stainthorpe, A. C., Lees, V., Salmond, G. P. C., Dalton, H., and Murrell, J. C. (1990). The Methane Monooxygenase Gene Cluster of Methylococcus Capsulatus (Bath). Gene 91, 27-34. doi:10.1016/0378-1119(90)90158-n

Sticher, P., Jaspers, M. C., Stemmler, K., Harms, H., Zehnder, A. J., and van der MeerVan der Meer, J. R. (1997). Development and Characterization of a Whole-Cell Bioluminescent Sensor for Bioavailable Middle-Chain Alkanes in Contaminated Groundwater Samples. Appl. Environ. Microbiol. 63 (10), 4053-4060. doi:10.1128/aem.63.10.4053-4060.1997

Stirling, D. I., Colby, J., and Dalton, H. (1979). A Comparison of the Substrate and Electron-Donor Specificities of the Methane Mono-Oxygenases from Three Strains of Methane-Oxidizing Bacteria. Biochem. J. 177 (1), 361-364. doi:10.1042/BJ1770361

Stolyar, S., Franke, M., and Lidstrom, M. E. (2001). Expression of Individual Copies of Methylococcus Capsulatus Bath Particulate Methane Monooxygenase Genes. J. Bacteriol. 183 (5), 1810-1812. doi:10.1128/JB.183.5.1810-1812.2001

Su, L., Jia, W., Hou, C., and Lei, Y. (2011). Microbial Biosensors: A Review. Biosens. Bioelectron. 26 (5), 1788-1799. doi:10.1016/j.bios.2010.09.005

Swaving, J., Weijers, C. A., van Ooyen, A. J., and De Bont, J. A. (1995). Complementation of Xanthobacter Py2 Mutants Defective in Epoxyalkane Degradation, and Expression and Nucleotide Sequence of the Complementing DNA Fragment. Microbiology (Reading) 141 ( Pt 2), 477-484. doi:10.1099/ 13500872-141-2-477

Tan, J.-L., Yong, Z.-X., and Liam, C.-K. (2016). Using a Chemiresistor-Based Alkane Sensor to Distinguish Exhaled Breaths of Lung Cancer Patients from Subjects with No Lung Cancer. J. Thorac. Dis. 8 (10), 2772-2783. doi:10.21037/ jtd.2016.10.30

Tani, A., Ishige, T., Sakai, Y., and Kato, N. (2000). Gene Structures and Regulation of the Alkane Hydroxylase Complex in Gene Structures and Regulation of the Alkane Hydroxylase Complex in Acinetobacter Sp. Strain M-1 183 (5), 1819-1823. doi:10.1128/JB.183.5.1819

Taylor, A. E., Arp, D. J., Bottomley, P. J., and Semprini, L. (2010). Extending the Alkene Substrate Range of Vinyl Chloride Utilizing Nocardioides Sp. Strain JS614 with Ethene Oxide. Appl. Microbiol. Biotechnol. 87, 2293-2302. doi:10.1007/s00253-010-2719-8

Tecon, R., Beggah, S., and van der MeerVan der Meer, J. R. (2010). "Bacterial Bioreporter Assays to Measure Hydrocarbons," in Handbook of Hydrocarbon 
and Lipid Microbiology (Springer Berlin Heidelberg), 3641-3653. doi:10.1007/ 978-3-540-77587-4_287

Tecon, R., and Van der Meer, J. (2008). Bacterial Biosensors for Measuring Availability of Environmental Pollutants. Sensors 8 (7), 4062-4080. doi: $10.3390 / \mathrm{s} 8074062$

Tecon, R., and van der Meer, J. R. (2006). Information from Single-Cell Bacterial Biosensors: What Is it Good for. Curr. Opin. Biotechnol. 17 (1), 4-10. doi:10.1016/j.copbio.2005.11.001

Throne-Holst, M., Wentzel, A., Ellingsen, T. E., Kotlar, H.-K., and Zotchev, S. B. (2007). Identification of Novel Genes Involved in Long-Chain N -Alkane Degradation by Acinetobacter Sp. Strain DSM 17874. Appl. Environ. Microbiol. 73 (10), 3327-3332. doi:10.1128/AEM.00064-07

Tourova, T. P., Sokolova, D. S., Semenova, E. M., Shumkova, E. S., Korshunova, A. V., Babich, T. L., et al. (2016). Detection of N-Alkane Biodegradation Genes AlkB and LadA in Thermophilic Hydrocarbon-Oxidizing Bacteria of the Genera Aeribacillus and Geobacillus. Microbiology 85 (6), 693-707. doi:10.1134/S0026261716060199

Vainberg, S., McClay, K., Masuda, H., Root, D., Condee, C., ZylstraZylstra, G. J., et al. (2006). Biodegradation of Ether Pollutants by Pseudonocardia Sp. Strain ENV478. Appl. Environ. Microbiol. 72 (8), 5218-5224. doi:10.1128/ AEM.00160-06

van Beilen, J. B., and Funhoff, E. G. (2007). Alkane Hydroxylases Involved in Microbial Alkane Degradation. Appl. Microbiol. Biotechnol. 74 (1), 13-21. doi:10.1007/s00253-006-0748-0

Van Beilen, J. B., Li, Z., Duetz, W. A., Smits, T. H. M., Witholt, B., and Bernard, W. (2003). Diversity of Alkane Hydroxylase Systems in the Environment. Oil Gas Sci. Tech. - Rev. IFP 58 (4), 427-440. doi:10.2516/ogst:2003026

van Beilen, J. B., Marin, M. M., Smits, T. H. M., Rothlisberger, M., Franchini, A. G., Witholt, B., et al. (2004). Characterization of Two Alkane Hydroxylase Genes from the Marine Hydrocarbonoclastic Bacterium Alcanivorax Borkumensis. Environ. Microbiol. 6 (3), 264-273. doi:10.1111/j.1462-2920.2004.00567.x

van Beilen, J. B., Panke, S., Lucchini, S., Franchini, A. G., Röthlisberger, M., and Witholt, B. (2001). Analysis of Pseudomonas Putida Alkane-Degradation Gene Clusters and Flanking Insertion Sequences: Evolution and Regulation of the Alk Genes the EMBL Accession Numbers for the Sequences Reported in This Paper Are AJ245436 [P. Putida (Oleovorans) GPol Alk Gene Clusters and Flanking DNA], AJ233397 (P. Putida P1 Alk Gene Clusters and Flanking DNA), AJ249793 (P. Putida P1 nahKJ Genes), AJ249825 [P. Putida (Oleovorans) GPo1 16S RNA Gene] and AJ271219 (P. Putida P1 16S RNA Gene). Microbiology 147, 1621-1630. doi:10.1099/00221287-147-6-1621

van Beilen, J. B., Wubbolts, M. G., and Witholt, B. (1994). Genetics of Alkane Oxidation byPseudomonas Oleovorans. Biodegradation 5, 161-174. doi:10.1007/bf00696457

van der Meer, J. R. (2010). "Bacterial Sensors: Synthetic Design and Application Principles," in Martyn Amos. Synthesis Lectures on Synthetic Biology (California; Morgan \& Claypool), 2, 1-167. doi:10.2200/ s00312ed1v01y201011sbi002

van der Meer, J. R., and Belkin, S. (2010). Where Microbiology Meets Microengineering: Design and Applications of Reporter Bacteria. Nat. Rev. Microbiol. 8 (7), 511-522. doi:10.1038/nrmicro2392

van der Meer, J. R. (2016). Towards Improved Biomonitoring Tools for an Intensified Sustainable Multi-Use Environment. Microb. Biotechnol. 9 (5), 658-665. doi:10.1111/1751-7915.12395

van der Meer, J. R., Tropel, D., and Jaspers, M. (2004). Illuminating the Detection Chain of Bacterial Bioreporters. Environ. Microbiol. 6 (10), 1005-1020. doi:10.1111/j.1462-2920.2004.00655.x

van Hylckama Vlieg, J. E. T., Leemhuis, H., SpelbergSpelberg, J. H. L., and Janssen, D. B. (2000). Characterization of the Gene Cluster Involved in Isoprene Metabolism in Rhodococcus Sp. Strain AD45. J. Bacteriol. 182 (7), 1956-1963. doi:10.1128/JB.182.7.1956-1963.2000

van Kessel, J. C., Ulrich, L. E., Zhulin, I. B., BasslerBassler, B. L., and Taylor, R. (2013). Analysis of Activator and Repressor Functions Reveals the Requirements for Transcriptional Control by LuxR, the Master
Regulator of Quorum Sensing in Vibrio Harveyi. mBio 4. doi:10.1128/ mBio.00378-13

Varjani, S. J. (2017). Microbial Degradation of Petroleum Hydrocarbons. Bioresour. Tech. 223 (January), 277-286. doi:10.1016/j.biortech.2016.10.037

Vogne, C., Beggah, S., and van der MeerVan der Meer, J. (2010). "Random and Site-Directed Mutagenesis of Transcriptional Regulator Proteins Implicated in Hydrocarbon Degradation Pathways," in Handbook Of Hydrocarbon And Lipid Microbiology. Editor Kenneth N. Timmis (Springer-Verlag Berlin Heidelberg), 4429-4444. doi:10.1007/978-3-540-77587-4_346

Wang, W., and Shao, Z. (2013). Enzymes and Genes Involved in Aerobic Alkane Degradation. Front. Microbiol. 4 (May). doi:10.3389/ fmicb.2013.00116

Wang, W., and Shao, Z. (2012). Genes Involved in Alkane Degradation in the Alcanivorax Hongdengensis Strain A-11-3. Appl. Microbiol. Biotechnol. 94 (2), 437-448. doi:10.1007/s00253-011-3818-x

Wang, W., and Shao, Z. (2014). The Long-Chain Alkane Metabolism Network of Alcanivorax Dieselolei. Nat. Commun. 5. doi:10.1038/ncomms6755

Wright, O., Delmans, M., Stan, G.-B., and Ellis, T. (2015). GeneGuard: A Modular Plasmid System Designed for Biosafety. ACS Synth. Biol. 4 (3), 307-316. doi:10.1021/SB500234S

Wu, W., Zhang, L., Yao, L., Tan, X., Liu, X., and Lu, X. (2015). Genetically Assembled Fluorescent Biosensor for In Situ Detection of Bio-Synthesized Alkanes. Sci. Rep. 5 (June), 10907. doi:10.1038/srep 10907

Yuste, L., Canosa, I., and Rojo, F. (1998). Carbon-Source-Dependent Expression of the PalkB Promoter from the Pseudomonas Oleovorans Alkane Degradation Pathway. J. Bacteriol. 180 (19), 5218-5226. doi:10.1128/JB.180.19.5218-5226.1998

Zhang, D., Fakhrullin, R. F., Özmen, M., Wang, H., Wang, J., Paunov, V. N., et al. (2011). Functionalization of Whole-Cell Bacterial Reporters with Magnetic Nanoparticles. Microb. Biotechnol. 4 (1), 89-97. doi:10.1111/j.17517915.2010.00228.x

Zhang, D., He, Y., Wang, Y., Wang, H., Wu, L., Aries, E., et al. (2012a). Whole-Cell Bacterial Bioreporter for Actively Searching and Sensing of Alkanes and Oil Spills. Microb. Biotechnol. 5 (1), 87-97. doi:10.1111/ j.1751-7915.2011.00301.x

Zhang, D., Zhao, Y., He, Y., Wang, Y., Zhao, Y., Zheng, Y., et al. (2012b). Characterization and Modeling of Transcriptional Cross-Regulation in Acinetobacter Baylyi ADP1. ACS Synth. Biol. 1 (7), 274-283. doi:10.1021/ sb3000244

Zhou, N.-Y., ·Chan, C. K., and Leak, D. J. (1996). "Cloning and Expression of the Genes Encoding the Propene Monooxygenase from Xanthobacter," in Py2. Appl Microbiol Biotechnol (Springer-Verlag), 44. doi:10.1007/ bf00172489

Zhou, N.-Y., Jenkins, A., Chan Kwo Chion, C. K. N., Leak, D. J., and Leak, D. J. (1999). The Alkene Monooxygenase from Xanthobacter Strain Py2 Is Closely Related to Aromatic Monooxygenases and Catalyzes Aromatic Monohydroxylation of Benzene, Toluene, and Phenol. Appl. Environ. Microbiol. 65 (4), 1589-1595. doi:10.1128/aem.65.4.1589-1595.1999

Conflict of Interest: The authors declare that the research was conducted in the absence of any commercial or financial relationships that could be construed as a potential conflict of interest.

Publisher's Note: All claims expressed in this article are solely those of the authors and do not necessarily represent those of their affiliated organizations, or those of the publisher, the editors and the reviewers. Any product that may be evaluated in this article, or claim that may be made by its manufacturer, is not guaranteed or endorsed by the publisher.

Copyright (c) 2022 Moratti, Scott and Coleman. This is an open-access article distributed under the terms of the Creative Commons Attribution License (CC $B Y$ ). The use, distribution or reproduction in other forums is permitted, provided the original author(s) and the copyright owner(s) are credited and that the original publication in this journal is cited, in accordance with accepted academic practice. No use, distribution or reproduction is permitted which does not comply with these terms. 